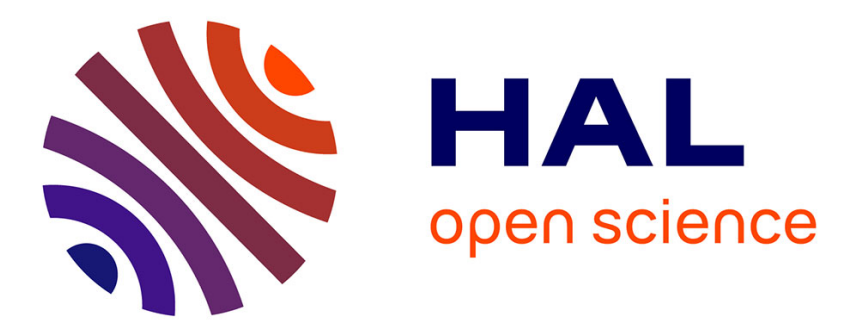

\title{
Directional Anisotropic Diffusion Applied to Segmentation of Vessels in 3D Images
}

Karl Krissian, Grégoire Malandain, Nicholas Ayache

\section{To cite this version:}

Karl Krissian, Grégoire Malandain, Nicholas Ayache. Directional Anisotropic Diffusion Applied to Segmentation of Vessels in 3D Images. RR-3064, INRIA. 1996. inria-00073628

\section{HAL Id: inria-00073628 \\ https://hal.inria.fr/inria-00073628}

Submitted on 24 May 2006

HAL is a multi-disciplinary open access archive for the deposit and dissemination of scientific research documents, whether they are published or not. The documents may come from teaching and research institutions in France or abroad, or from public or private research centers.
L'archive ouverte pluridisciplinaire HAL, est destinée au dépôt et à la diffusion de documents scientifiques de niveau recherche, publiés ou non, émanant des établissements d'enseignement et de recherche français ou étrangers, des laboratoires publics ou privés. 
INSTITUT NATIONAL DE RECHERCHE EN INFORMATIQUE ET EN AUTOMATIQUE

\title{
Directional Anisotropic Diffusion applied to segmentation of vessels in 3D images
}

\author{
Karl KRISSIAN, Grégoire MALANDAIN, Nicholas AYACHE
}

\section{$\mathbf{N}^{\circ} 3064$}

décembre 1996

THÈME 3

\section{apport}

derecherche 



\title{
Directional Anisotropic Diffusion applied to segmentation of vessels in 3D images
}

\author{
Karl KRISSIAN $^{*}$, Grégoire MALANDAIN ${ }^{* *}$, \\ Nicholas AYACHE ${ }^{* * *}$
}

Thème 3 - Interaction homme-machine, images, données, connaissances

Projet Epidaure

Rapport de recherche $n^{\circ} 3064$ - décembre 1996 - 48 pages

\begin{abstract}
Anisotropic Diffusion is a new method derived from the convolution with a Gaussian, which allows to reduce the noise in the image without blurring the frontiers between different regions. This process can be applied in medical image analysis to segment the different anatomical structures. In this report, we introduce a new implementation of the anisotropic diffusion which allows us to reduce the noise and better preserve small structures like vessels in 3D images. This method is based on the differentiation of the diffusion in the direction of the gradient, and in the directions of the minimum and the maximum curvature. This algorithm gave good results on both synthetic and real images. We append to this work a part of the master's thesis of the first author (in French) which details several points of interest.
\end{abstract}

Key-words: Anisotropic diffusion, scale-space theory, computer vision, segmentation

(Résumé : tsvp)

\footnotetext{
*Email : kkrissia@sophia.inria.fr

** Email : greg@sophia.inria.fr

*** Email : na@sophia.inria.fr
} 


\section{Etude de la diffusion anisotrope appliquée à la segmentation de vaisseaux dans les images médicales tridimensionnelles}

Résumé : La diffusion anisotrope est une nouvelle technique dérivée du produit de convolution avec une fonction gaussienne qui permet de restaurer les images bruitées en préservant le contraste de l'image. Ce processus peut être utilisé dans le domaine de l'imagerie médicale pour segmenter différentes structures anatomiques. Dans ce rapport, nous introduisons une nouvelle mise en œuvre de la diffusion anisotrope qui permet de réduire le bruit et de mieux préserver les petites structures comme les vaisseaux dans les images tridimensionnelles. Cette technique est basée sur la différenciation de la diffusion selon les directions du gradient et de courbure minimale et maximale. Cet algorithme donne de bons résultats aussi bien sur des images synthétiques que sur des images réelles. La première partie du mémoire de DEA du premier auteur, qui détaille certaines démonstrations, se trouve en annexe.

Mots-clé : Diffusion anisotrope, analyse multi-échelle, traitement d'images, segmentation 


\section{Contents}

1 Anisotropic Diffusion 5

1.1 Introduction . . . . . . . . . . . . . . 5

1.1.1 The process proposed by Perona et Malik . . . . . . . . 5

1.1.2 Improvement proposed by Catté et al. . . . . . . . . . . 6

1.1.3 Motivation ................ 7

1.1.4 Other works in three-dimensional anisotropic diffusion . . . 7

2 Approach 8

2.1 The computation of the second derivatives in the direction of principal curvatures $u_{e_{1} e_{1}}$ and $u_{e_{2} e_{2}} \ldots \ldots \ldots \ldots \ldots$

2.2 Estimation of the parameters of the diffusion functions . . . . . . 10

2.3 The choice of the diffusion functions . . . . . . . . . . . . . 10

3 Experiments 11

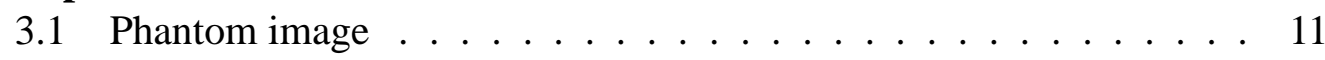

3.2 Real image of vessels . . . . . . . . . . . . . . . 12

4 Future research $\quad 15$

$\begin{array}{lr}\text { A Diffusion Anisotrope } & 17\end{array}$

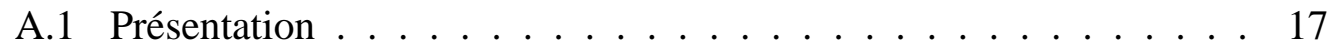

A.1.1 Diffusion isotrope . . . . . . . . . . . 17

A.1.2 Diffusion anisotrope ................ 20

A.2 Approche variationnelle . . . . . . . . . . . . . 20

A.2.1 Présentation du problème . . . . . . . . . . . 20

A.2.2 Les équations d'Euler-Lagrange . . . . . . . . . . . . . . . 22

A.2.3 Retour à la minimisation de $E \ldots \ldots . . . . . . . . . .24$

A.3 Choix de la fonction de diffusion . . . . . . . . . . . . 26

A.3.1 Critères de stabilité . . . . . . . . . . . . 26

A.3.2 Critères de restauration . . . . . . . . . . . . . . . 27

A.3.3 Différentes fonctions proposées . . . . . . . . . . 28

A.4 Mise en œuvre du processus de diffusion . . . . . . . . . . . . . . . 30

A.4.1 Approximation numérique en dimension 1 . . . . . . . . 30

A.4.2 Généralisation en dimension $\mathrm{n} \ldots \ldots . \ldots 30$ 


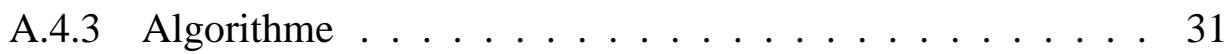

A.5 Principaux paramètres de la procédure . . . . . . . . . . . . . . 34

A.5.1 Le seuil $k$ et la fonction de diffusion . . . . . . . . . . . . . . . . 34

A.5.2 Le nombre de pas . . . . . . . . . . . . . . . . . . 38

A.6 Autre approche ... . . . . . . . . . . . . . . . . 40

A.7 Défauts et perspectives . . . . . . . . . . . . . . . . 41

A.8 Représentation graphique des fonctions de diffusion . . . . . . . . . 43

$\begin{array}{ll}\text { Bibliographie } & 47\end{array}$ 


\section{Anisotropic Diffusion}

\subsection{Introduction}

This work was done after a master's thesis [Kri96] defended in septembre 1996 (part of this report can be found in appendix). In particular, appendix [A.2.3] presents a demontration of the equivalence between the anisotropic diffusion equation of Perona and Malik (2) and equation (7) which differentiates the diffusion in three directions.

We first present and discuss previous work in anisotropic diffusion. Second, we introduce our motivation for a new scheme based on the differentiation of the diffusion in the directions of the minimum and the maximum curvature. Finally, we present experimental results on synthetic and real data, before closing with perspectives.

\subsubsection{The process proposed by Perona et Malik}

It is well known that the Gaussian convolution is equivalent to the resolution of the heat diffusion equation. If $u$ represents the intensity function of the image, then the heat diffusion equation is written:

$$
\frac{\partial u}{\partial t}=\Delta u
$$

Perona et Malik [PM90] have introduced the following diffusion equation:

$$
\frac{\partial u}{\partial t}=\operatorname{div}(g(|\nabla u|) . \nabla u)
$$

The convergence of this process is ensured for diffusion functions $g$ with given properties [DF95]. In order to show this convergence, equation (2) is expressed as a minimization of the following energy:

$$
E(u)=\lambda \int_{\Omega} \Phi(|\nabla u|) d \Omega
$$

where $\frac{\Phi^{\prime}(|\nabla u|)}{|\nabla u|}=g(|\nabla u|)$. 
Equation (2) is a descent of gradient along the energy surface $E(u)$.

In order to study in 2D images the restoration criteria for this process, we can rewrite it as a sum of second derivatives of the intensity in certain directions weighted by coefficients depending on function $\Phi$.

$$
\frac{\partial u}{\partial t}=\Phi^{\prime \prime}(|\nabla u|) u_{\xi \xi}+\frac{\Phi^{\prime}(|\nabla u|)}{|\nabla u|} u_{\eta \eta}
$$

where $\xi=\frac{\nabla u}{|\nabla u|}$ is a unit vector in the direction of the gradient, and $\eta$ is a normal vector orthogonal to the gradient.

In appendix [A.2.3], we show that this result can be generalized in a space of dimension greater than two:

$$
\frac{\partial u}{\partial t}=\Phi^{\prime \prime}(|\nabla u|) u_{\xi \xi}+\frac{\Phi^{\prime}(|\nabla u|)}{|\nabla u|}\left(\Delta u-u_{\xi \xi}\right)
$$

This equation shows that the equation (2) is isotropic in the hyperplane orthogonal to the gradient of the intensity, i.e. the hyperplane tangent to the local isosurface. We learned recently that this equivalence was also verified in three dimensions by Teboul, Blanc-Féraud, Aubert and Barlaud in [TBFAB96] but the demonstration presented in the appendix is more general and can be applied to any dimension $n \geq 2$.

\subsubsection{Improvement proposed by Catté et al.}

The principle of Catté et al [CCLM92] is to reduce the noise participation in the computation of the parameter of the diffusion function $\Phi$. They propose the following diffusion process where the parameter of the diffusion function is the norm of the gradient of the smoothed image (the convolution of the image with a Gaussian) instead of the norm of the gradient:

$$
\frac{\partial u}{\partial t}=\operatorname{div}\left(g\left(\left\|\nabla u^{*}\right\|\right) \cdot \nabla u\right)
$$

where

$$
u^{*}=G_{\sigma} * u \text {. }
$$

This process gives experimentally better results than equation (2) and is proved to be consistent and convergent. 


\subsubsection{Motivation}

In the field of medical image analysis, we are especially interested in the use of anisotropic diffusion for three-dimensional images and in the preservation of small structures like blood vessels.

We denote $e_{1}$ and $e_{2}$ the two vectors in the principal directions of curvature of the plane orthogonal to the gradient of intensity. $e_{1}$ will be a unit vector in the direction of the maximum curvature $k_{1}$, and $e_{2}$ a unit vector in the direction of minimum curvature $k_{2}$. $\left(\xi, e_{1}, e_{2}\right)$ is a base of the $3 \mathrm{D}$ space $\mathbb{R}^{3}$.

The equation (5) can be written as

$$
\frac{\partial u}{\partial t}=\Phi^{\prime \prime}(|\nabla u|) u_{\xi \xi}+\frac{\Phi^{\prime}(|\nabla u|)}{|\nabla u|}\left(u_{e_{1} e_{1}}+u_{e_{2} e_{2}}\right)
$$

We transform this process in a more general process where each second derivative of the intensity is multiplied by a different function.

$$
\frac{\partial u}{\partial t}=C_{\xi}(|\nabla u|) u_{\xi \xi}+C_{e_{1}}\left(|\nabla u|,\left|k_{1}\right|\right) u_{e_{1} e_{1}}+C_{e_{2}}\left(|\nabla u|,\left|k_{2}\right|\right) u_{e_{2} e_{2}}
$$

In order to privilege the direction of minimum curvature in the diffusion process, we impose a coefficient $C_{e_{2}}$ greater than $C_{e_{1}}$. The motivation of that choice is to smooth more along the direction $e_{2}$ than along the direction $e_{1}$, which is intuitive for vessel-like structures (see Fig. 1).

Our new process includes the process of Perona and Malik and is more general. In this new process, the conditions of convergence and of luminance conservation must be studied. In this article, we focus on experimental results which tend to show that our new approach is consistent.

\subsubsection{Other works in three-dimensional anisotropic diffusion}

There are very few publications related to three-dimensional anisotropic diffusion. Extensions of curve evolution schemes [NVV96] to 3D have been studied. They essentially deal with the mean curvature [Gra89, Set85] or the Gaussian curvature [CS93]. 


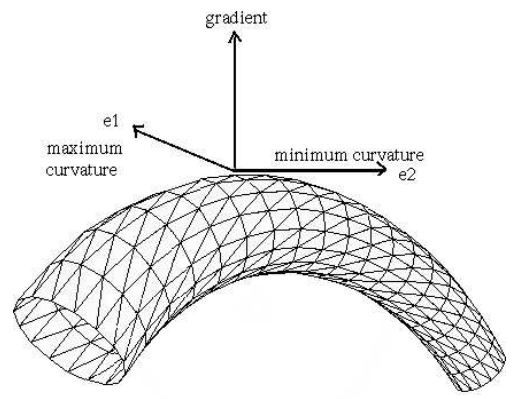

Figure 1: Illustration of the direction of the gradient, and the directions of the minimum and the maximum curvature.

\section{Approach}

\subsection{The computation of the second derivatives in the direction of principal curvatures $u_{e_{1} e_{1}}$ and $u_{e_{2} e_{2}}$}

The first idea to compute $u_{e_{1} e_{1}}$ and $u_{e_{2} e_{2}}$ was to use the formula:

$$
u_{v v}=v^{t} H v
$$

where $\mathrm{H}$ is the Hessian of the image at the current point.

In fact, we use instead the following expression which avoids to compute the vectors $e_{1}$ and $e_{2}$ :

$$
\begin{aligned}
& u_{e_{1} e_{1}}=-|\nabla u| \cdot k_{1} \\
& u_{e_{2} e_{2}}=-|\nabla u| \cdot k_{2}
\end{aligned}
$$

Demonstration of equations (8) and (9) : This property can be easily proved in two dimensions by using Gauge coordinates [Rom96], and it can be applied to the plane $\left(M, \nabla u, e_{1}\right)$ (respectively $\left.\left(M, \nabla u, e_{2}\right)\right)$ which contains the current point $\mathrm{M}$ and is parallel to the vectors $\nabla u$ and $e_{1}$ (respectively $e_{2}$ ).

In two dimensions, at each point $M$ of an isophote, we note $v$ an axis tangent to the isophote and $\xi$ an axis orthogonal to $v$ in the direction of the gradient. Locally, if $u_{\xi} \neq 0$, we can write the isophote as a function $\xi(v)$ in our new reference, and the local isophote is characterized by the expression 
$u(v, \xi(v))=$ constant with $u_{v}(M)=0$. By implicit differentiation and application of the chain rule, we obtain in the point $\mathrm{M}$ :

$$
\begin{aligned}
u_{v}+u_{\xi} \cdot \xi^{\prime}=0 & \rightarrow \xi^{\prime}=-\frac{u_{v}}{u_{\xi}} \\
& \rightarrow \xi^{\prime}(M)=0
\end{aligned}
$$

and

$$
u_{v v}+2 \cdot u_{v \xi} \xi^{\prime}+u_{\xi \xi} \xi^{\prime 2}+u_{\xi} \xi^{\prime \prime}=0
$$

therefore, if $\kappa$ denotes the isophote curvature:

$$
\kappa(M)=\xi^{\prime \prime}(M)=-\frac{u_{v v}}{u_{\xi}}
$$

For the computation of $k_{1}$ and $k_{2}$, we use the following formulas given in [TG95]. $k_{1}$ and $k_{2}$ are the solutions of an equation of order two:

$$
k_{i}=H \pm \sqrt{\Delta} \text { with } \Delta=H^{2}-K .
$$

where $K$ and $H$ are the Gaussian and the mean curvature. They can be computed directly from the first and second derivatives of the image.

$$
\begin{array}{r}
K=\frac{1}{h^{2}}\left[\begin{array}{r}
f_{x}^{2}\left(f_{y y} f_{z z}-f_{y z}^{2}\right)+2 f_{y} f_{z}\left(f_{x z} f_{x y}-f_{x x} f_{y z}\right)+ \\
f_{y}^{2}\left(f_{x x} f_{z z}-f_{x z}^{2}\right)+2 f_{x} f_{z}\left(f_{y z} f_{x y}-f_{y y} f_{x z}\right)+ \\
\left.f_{z}^{2}\left(f_{x x} f_{y y}-f_{x y}^{2}\right)+2 f_{x} f_{y}\left(f_{x z} f_{y z}-f_{z z} f_{x y}\right)\right]
\end{array}\right. \\
H=\frac{1}{2 h^{3 / 2}}\left[\begin{array}{r}
f_{x}^{2}\left(f_{y y}+f_{z z}\right)-2 f_{y} f_{z} f_{y z}+ \\
f_{y}^{2}\left(f_{x x}+f_{z z}\right)-2 f_{x} f_{z} f_{x z}+ \\
f_{z}^{2}\left(f_{x x}+f_{y y}\right)-2 f_{x} f_{y} f_{x y}
\end{array}\right]
\end{array}
$$

where $h=f_{x}^{2}+f_{y}^{2}+f_{z}^{2} . \mathbf{x}, \mathbf{y}, \mathbf{z}$ have the same role in these equations so these formulas do not give a specific play to a particular direction of the space. 


\subsection{Estimation of the parameters of the diffusion functions}

Intuitively, we want to eliminate the noise in the estimation of the parameters of the different diffusion functions $C_{\xi}, C_{e_{1}}$ and $C_{e_{2}}$. We use the same idea as Catté et al, i.e. we compute these values on a smoothed image $u^{*}$. The equation (7) becomes:

$$
\frac{\partial u}{\partial t}=C_{\xi}\left(\left\|\nabla u^{*}\right\|\right) u_{\xi \xi}+C_{e_{1}}\left(\left\|\nabla u^{*}\right\|,\left|k_{1}^{*}\right|\right) u_{e_{1} e_{1}}+C_{e_{2}}\left(\left\|\nabla u^{*}\right\|,\left|k_{2}^{*}\right|\right) u_{e_{2} e_{2}}
$$

where $\left\|\nabla u^{*}\right\|,\left|k_{1}^{*}\right|$ and $\left|k_{2}^{*}\right|$ are respectively the norm of the gradient, the maximum and the minimum curvature of the convolved image with a Gaussian $G_{\sigma}$.

In order to be able to compare our process with the process of Perona and Malik, we will use the following equation without smoothing the gradient to compute its norm:

$$
\frac{\partial u}{\partial t}=C_{\xi}(\|\nabla u\|) u_{\xi \xi}+C_{e_{1}}\left(\|\nabla u\|,\left|k_{1}^{*}\right|\right) u_{e_{1} e_{1}}+C_{e_{2}}\left(\|\nabla u\|,\left|k_{2}^{*}\right|\right) u_{e_{2} e_{2}}
$$

\subsection{The choice of the diffusion functions}

We use the following principle to choose the three diffusion functions:

1. we choose a threshold $k$ on the value of the gradient magnitude and we suppose that $|\nabla u|>k$ in regions of frontier between different structures (or contours).

2. if $|\nabla u|<k$, we use functions which are equivalent to the process of Perona and Malik and which ensure properties of convergence.

$$
\begin{aligned}
C_{\xi} & =\Phi^{\prime \prime}(|\nabla u|) \\
C_{e_{1}}=C_{e_{2}} & =\frac{\Phi^{\prime}(|\nabla u|)}{|\nabla u|}
\end{aligned}
$$

3. if $|\nabla u|>k$, we compute the values of the principal curvature of the smoothed image $k_{1}^{*}$ and $k_{2}^{*}$ and use the following coefficients:

$$
C_{\xi}=\Phi^{\prime \prime}(|\nabla u|)
$$




$$
\begin{aligned}
& C_{e_{1}}=\frac{\Phi^{\prime}(|\nabla u|)}{|\nabla u|} h_{1}\left(\left|k_{1}^{*}\right|,\left|k_{2}^{*}\right|\right) \\
& C_{e_{2}}=\frac{\Phi^{\prime}(|\nabla u|)}{|\nabla u|} h_{2}\left(\left|k_{1}^{*}\right|,\left|k_{2}^{*}\right|\right)
\end{aligned}
$$

where $h_{1}$ and $h_{2}$ are functions from $\mathbb{R}^{2}$ to $\mathbb{R}$ which satisfy the properties:

$$
\begin{array}{rll}
\forall k_{1}, k_{2} \in \mathbb{R} \text { with } k_{1}>k_{2}, \quad \text { we have } & h_{1}\left(k_{1}, k_{2}\right), h_{2}\left(k_{1}, k_{2}\right) \in[0,1] \\
\text { and } \quad & h_{2}\left(k_{1}, k_{2}\right)>h_{1}\left(k_{1}, k_{2}\right)
\end{array}
$$

\section{Experiments}

For the experiments, we chose the functions of Green [Gre90] (Fig. 2) which satisfy the properties of stability $(18,19)$ and restoration $(20)$ for the Perona and Malik process defined in [DF95].

$$
\begin{aligned}
\Phi^{\prime \prime}(|\nabla u|) & \geq 0 \\
\Phi^{\prime}(|\nabla u|) & \geq 0 \\
\lim _{x \rightarrow \infty} \Phi^{\prime \prime}(x)=0 \text { and } \lim _{x \rightarrow \infty} \frac{\Phi^{\prime}(x)}{x} & =0 \text { and } \lim _{x \rightarrow \infty} \frac{x \Phi^{\prime \prime}(x)}{\Phi^{\prime}(x)}=0
\end{aligned}
$$

We chose $h_{1}$ and $h_{2}$ as constant functions of values 0 and 1 to ensure that the diffusion along the direction of maximum curvature is stopped near the frontier of the vessels. We plan to experiment functions depending on the absolute values of the curvatures of the smoothed image $k_{1}^{*}$ and $k_{2}^{*}$.

\subsection{Phantom image}

We created a phantom image containing three torus with the same small radius (2 voxels) and different large radii (7, 14 and 22 voxels). Those are like vessels with small radius and high intensity (100 for the torus and 0 for the background). The image has been smoothed with a Gaussian of standard deviation 0.7 (to simulate 


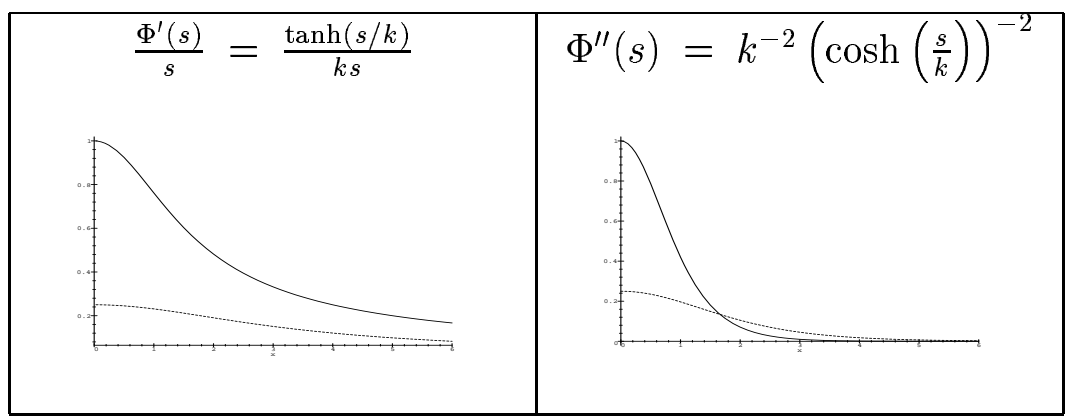

Figure 2: Diffusion function of Green with threshold $k=1$ (plain line) and $k=2$ (doted line).

partial volume effect) and blurred with an additive Gaussian white noise of standard deviation 300 .

The figure 3 represents isosurfaces taken from the original and processed images, with the same threshold $h=30$, which corresponds roughly to the "contours" defined by $|\nabla u|>k$ for $k=20$. We can see a better conservation of the "vessels" size on the bottom right, for a similar level of noise reduction between the bottom left and the bottom right images of figure 3 .

\subsection{Real image of vessels}

We applied our algorithm to a $64^{3}$ subvolume taken from a 3D angiography of the brain (courtesy of Dr. Yves Trousset, General Electric Medical Systems Europe, Buc, France).

The standard deviation $\sigma$ of the smoothed image shown in fig. 4 has been chosen in order to obtain a scale which can be compared to the scale $t$ of diffusion used for the two images in fig. 5. So we have the relation $t=\frac{\sigma^{2}}{2}$.

The expected advantage of anisotropic diffusion (figure 5, left) versus Gaussian convolution (figure 4, right) is clearly shown. Figure 5 (right) illustrates the advantage of privileging anisotropic diffusion within the plane tangent to the "contour" isosurfaces in the direction of minimum curvature (in absolute value). In particular, one can see a much better preservation of the vessels connectivity for a comparable noise reduction. Also, a close comparison between (figure 5, left) and (figure 5, 

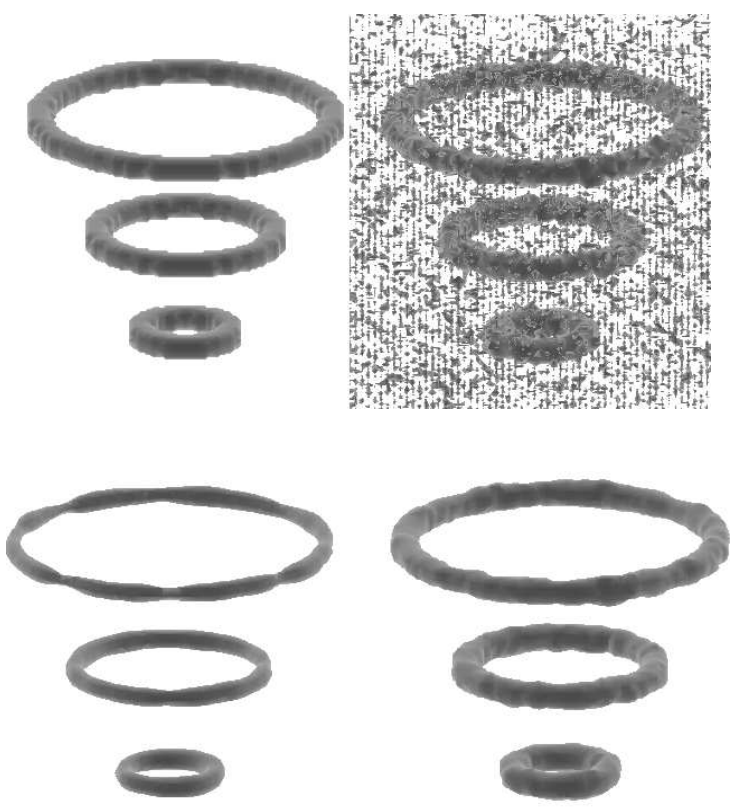

Figure 3: On the top left, the synthetic image with three torus. On the top right, the same image smoothed and blurred. On the bottom left, Perona and Malik diffusion with Green function. On the bottom right, direction oriented process privileging the direction of minimum curvature (in absolute value), in the plane tangent to the "contour" isosurface. 

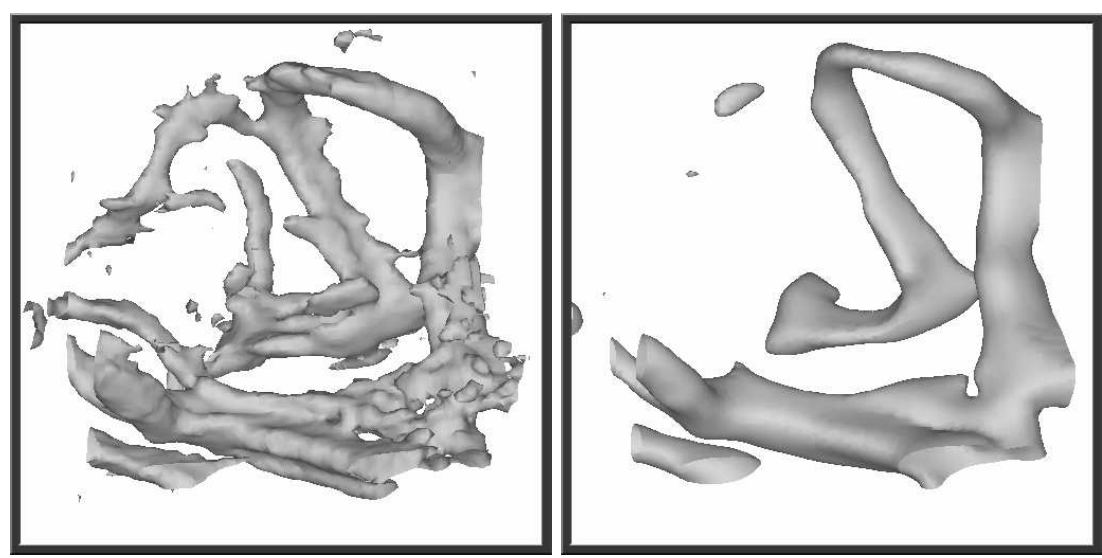

Figure 4: Isosufaces with threshold of 1000. On the left the initial image. On the right the initial image convolved with a Gaussian of standard deviation 2.
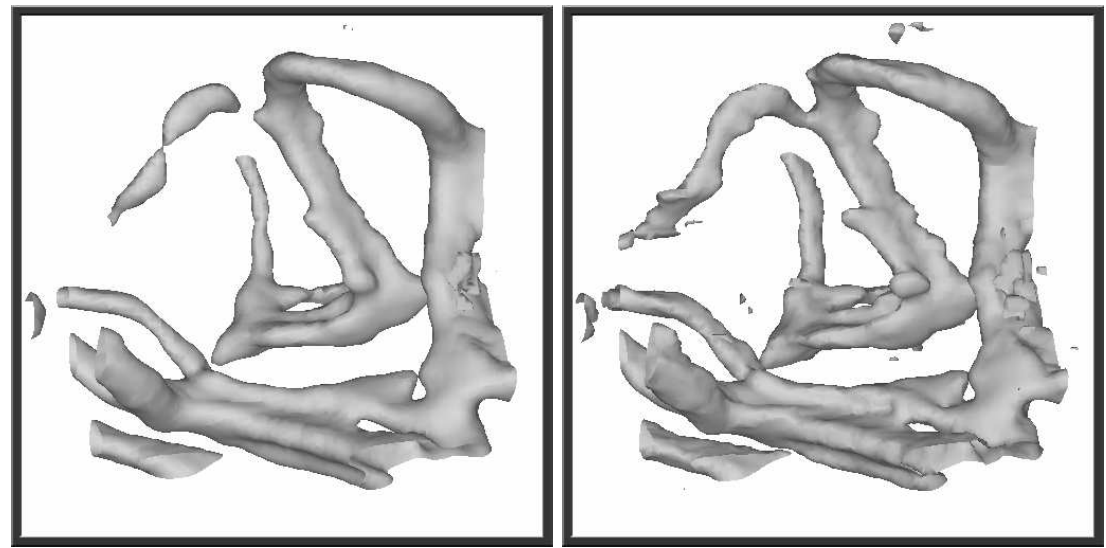

Figure 5: Isosufaces with threshold of 1000. On the left anisotropic diffusion with Green function. On the right direction oriented process privileging the direction of minimum curvature (in absolute value), in the plane tangent to the "contour" isosurface. 
right) shows a better conservation of the diameter size of the small vessels like the vertical one in the central part of the figures.

\section{Future research}

This article is a preliminary experimental work presented here to propose a new idea (anisotropic diffusion in the the hyperplane tangent to the local isosurface) with encouraging experimental results. This is now motivating

1. a more theoretical work to establish a rigorous framework for which consistency and convergence could be proved;

2. a more thorough experimental study proving the actual superiority of this approach to extract small anatomical structures in 3D medical images.

This will be the purpose of our future work. 


\section{A Diffusion Anisotrope}

This appendix contains the first chapter (in french) of the work of a master's thesis [Kri96] defended in septembre 1996.

\section{A.1 Présentation}

\section{Notations}

Dans tout ce chapitre, nous utiliserons les notations suivantes :

$\begin{array}{ll}\mathrm{n} & \text { dimension de l'image, } \\ \mathbb{R} & \text { ensemble des réels, } \\ \bar{x} & \text { un vecteur de } \mathbb{R}^{n} \text { ou un point de l'image, } \\ u(\bar{x}, t) & \text { fonction intensité de l'image, fonction de } \mathbb{R}^{n+1} \text { dans } \mathbb{R}, \\ \Omega & \text { domaine de définition de } u_{t}(\bar{x})=u(\bar{x}, t), \\ h_{k} & \text { taille d'un pixel dans la direction de la dimension } \mathrm{k}, \\ d x_{k} & \text { petite variation de la k-ième composante du vecteur } \bar{x} \\ \Delta u & \text { opérateur laplacien de la fonction } \mathrm{u}, \\ \nabla u & \text { vecteur gradient de la fonction } \mathrm{u}, \\ d i v(u) & \text { opérateur divergence de la fonction } \mathrm{u}, \\ u_{x}=\frac{\partial u}{\partial x} & \begin{array}{l}\text { dérivée partielle de u par rapport à la composante } \mathrm{x}, \\ x_{i}\end{array} \\ \bar{x}+d x_{i} & \text { i-ème composante du vecteur } \mathrm{x}, \\ & \text { le vecteur }\left(x_{1}, \cdots, x_{i}+d x_{i}, \cdots, x_{n}\right),\end{array}$

\section{A.1.1 Diffusion isotrope}

Principe

La diffusion isotrope d'une image s'effectue à l'aide d'un produit de convolution de l'image par un opérateur Gaussien de moyenne nulle et d'écart-type $\sigma$.

On note $u(\bar{x})$ la fonction intensité de l'image au point $\bar{x}$.

L'opérateur Gaussien de moyenne nulle et d'écart-type $\sigma$ est donné par

$$
G_{\sigma}(\bar{x})=\frac{1}{\sqrt{2 \pi} \sigma} \exp \frac{-<\bar{x}, \bar{x}>}{2 \sigma^{2}}
$$

où $<\bar{x}, \bar{x}>$ est le produit scalaire euclidien du vecteur $\bar{x}$ de $\mathbb{R}^{n}$. 
Le produit de convolution de deux fonctions de $\mathbb{R}^{n}$ dans $\mathbb{R}$ sur $\Omega \in \mathbb{R}^{n}$ est défini par la fonction

$$
(f * g)\left(\overline{x_{0}}\right)=\int_{\Omega} f\left(\overline{x_{0}}-\bar{x}\right) \cdot g(\bar{x}) d \bar{x}
$$

Effectuer un tel produit de convolution avec une fonction Gaussienne de moyenne nulle et d'écart-type $\sigma$ est équivalent à résoudre l'équation (21) à une échelle $t=\frac{\sigma^{2}}{2}$.

Equation de propagation de la chaleur :

$$
\frac{\partial u}{\partial t}=\Delta u
$$

On rappelle les définitions dans $R^{3}$ des opérateurs suivants :

$$
\begin{aligned}
\Delta u & =\frac{\partial^{2} u}{\partial x^{2}}+\frac{\partial^{2} u}{\partial y^{2}}+\frac{\partial^{2} u}{\partial z^{2}} \\
& =\operatorname{div}(\nabla(u)) \\
\operatorname{div}(\overrightarrow{\mathbf{v}}) & =\frac{\partial v_{x}}{\partial x}+\frac{\partial v_{y}}{\partial y}+\frac{\partial v_{z}}{\partial z} \\
\nabla(u) & =\frac{\partial u}{\partial x} \overrightarrow{\mathbf{i}}+\frac{\partial u}{\partial y} \cdot \overrightarrow{\mathbf{j}}+\frac{\partial u}{\partial z} \cdot \overrightarrow{\mathbf{k}}
\end{aligned}
$$

où $(\overrightarrow{\mathbf{i}}, \overrightarrow{\mathbf{j}}, \overrightarrow{\mathbf{k}})$ est une base orthonormée de $\mathbb{R}^{3}$.

Le calcul du produit de convolution par une Gaussienne de dimension $\mathrm{n} \operatorname{sur} \Omega=$ $\left[a_{1}, b_{1}\right] \times \cdots \times\left[a_{n}, b_{n}\right]$ peut se décomposer en $\mathrm{n}$ produits de convolution de dimension 1 sur chacun des intervalles $\left[a_{1}, b_{1}\right] \cdots\left[a_{n}, b_{n}\right]$. Ceci permet de réduire notablement le nombre d'opérations à réaliser pour effectuer cette convolution.

Défauts

Cependant, si le lissage par un opérateur Gaussien permet de réduire le bruit dans les images de faible complexité, il opère de manière identique dans toutes les directions et ne préserve pas les discontinuités ni le contraste des images.

Afin de résoudre les problèmes du lissage, une solution est de transformer l'image à l'aide d'une équation aux dérivées partielles permettant de diffuser de manière non-uniforme, en privilégiant certaines directions. 


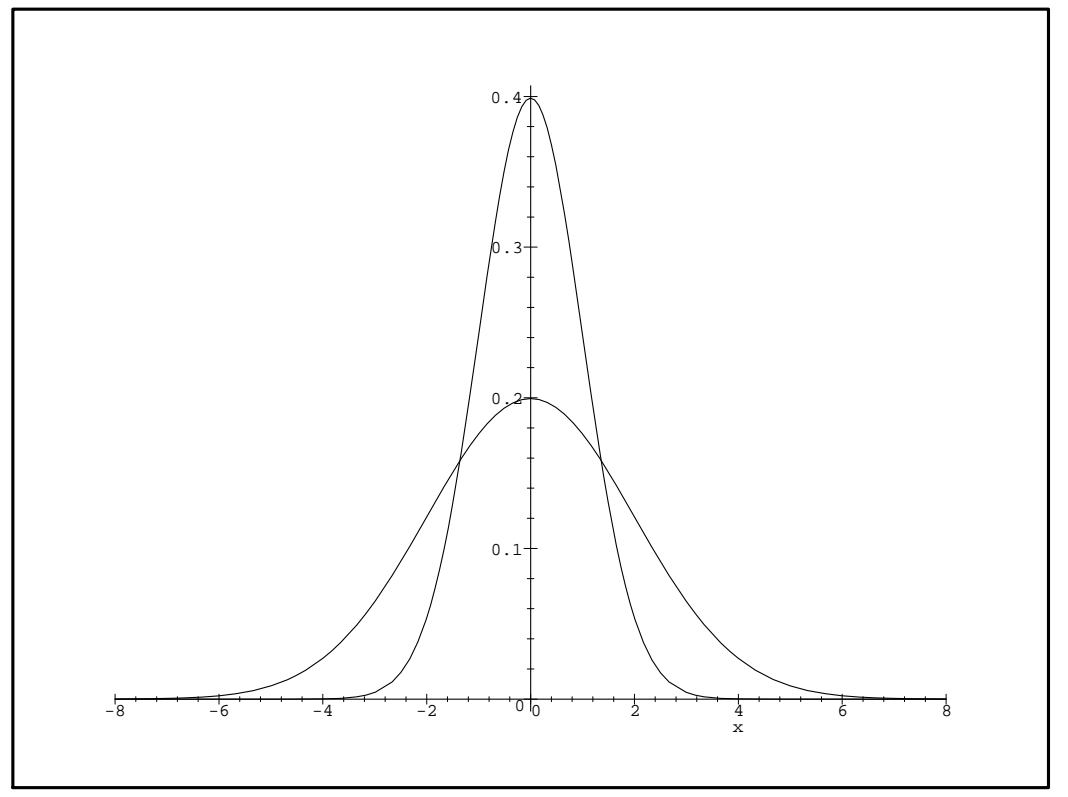

Figure 6: Fonction Gaussienne monodimensionnelle avec $\sigma=1$ et $\sigma=2$. 


\section{A.1.2 Diffusion anisotrope}

La diffusion anisotrope s'inspire de la diffusion isotrope en introduisant dans l'équation 21 une fonction de diffusion de $\mathbb{R}$ dans $\mathbb{R}$ dépendant de la norme du gradient de l'image choisie de manière à mieux préserver le contraste de l'image (voir fig 7).

Principe de la diffusion anisotrope

La nouvelle équation de diffusion s'écrit :

$$
\frac{\partial u}{\partial t}=\operatorname{div}(g(|\nabla u|) \cdot \nabla(u))
$$

où la fonction $\mathbf{g}$ est appelée fonction de diffusion.

Typiquement, on suppose que les variations du gradient d'intensité de l'image dues au bruit sont inférieures à un seuil noté $\mathbf{k}$ qui est lui-même inférieur au gradient introduit par les discontinuités de l'image non bruitée.

D'une part, la fonction g sera choisie de manière à diffuser très peu lorsque $|\nabla u|$ est très supérieur à $\mathbf{k}$ afin de limiter la diffusion dans les zones à forts gradients. D'autre part, elle devra tendre vers une constante non nulle lorsque $|\nabla u|$ est proche de zéro, agissant comme l'équation 21 de propagation de la chaleur.

L'approche variationnelle présentée ci-après permet de mieux comprendre ce processus et de préciser les contraintes nécessaires pour la fonction de diffusion.

\section{A.2 Approche variationnelle}

\section{A.2.1 Présentation du problème}

Cette approche est expliquée dans le rapport de recherche de R. Deriche et O. Faugeras [DF95].

Elle consiste à interpréter la diffusion anisotrope comme une descente de gradient afin de minimiser une énergie.

On note $u$, la fonction de $\mathbb{R}^{2}$ dans $\mathbb{R}$ définie sur le rectangle $\Omega=(0, a) \times(0, b)$. $u(\bar{x})$ représente l'intensité de l'image au point $\bar{x}=\left(x_{1}, \cdots, x_{n}\right)$ où $n$ est la dimension de l'image.

On cherche à trouver l'image originale non bruitée $u$ à partir de l'image bruitée $v$ 


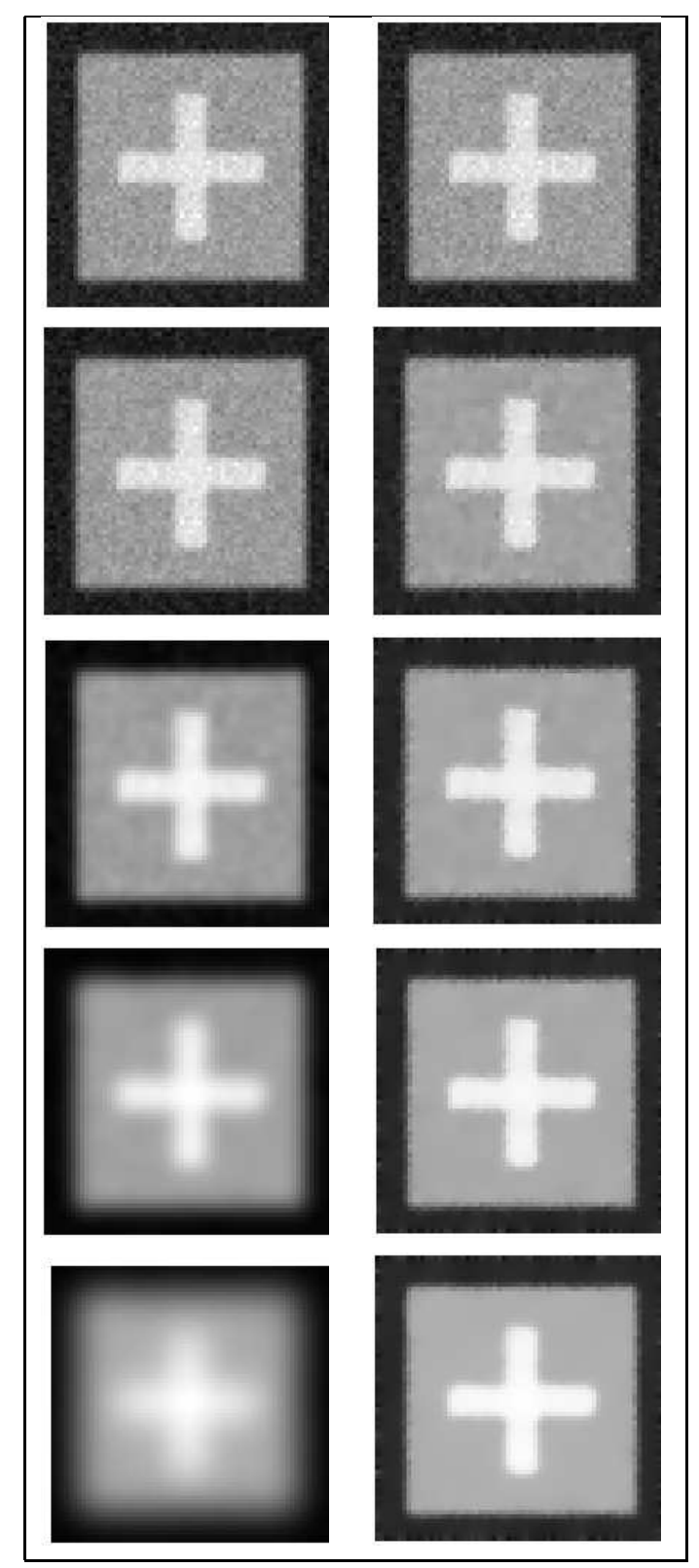

Figure 7: Résultats à gauche du produit de convolution de l'image par une Gaussienne, et à droite d'un filtrage anisotrope à une échelle t identique. 
dont on dispose.

On modélise $v$ par la formule :

$$
v=P u+\nu
$$

où $\mathrm{P}$ est un opérateur linéaire (l'opérateur de convolution par exemple) et $\nu$ est un bruit généralement considéré comme Gaussien de moyenne nulle.

On ramène le problème à celui de la minimisation de l'énergie $E(u)$ dont l'expression est la suivante :

$$
E(u)=\frac{1}{2}\|v-P u\|^{2}+\lambda \int_{\Omega} \Phi(|\nabla u|) d \Omega
$$

le premier terme de $E(u)$ est un terme d'attache aux données et le second terme prend en compte le lissage anisotrope de l'image.

On cherche une fonction $\Phi$ qui permette d'implémenter une méthode stable et convergente pour le calcul du minimum, tout en préservant le contraste de l'image.

\section{A.2.2 Les équations d'Euler-Lagrange}

Le problème de Lagrange consiste à trouver l'extremum de l'expression :

$$
I(y)=\int_{x_{0}}^{x_{1}} f\left(x, y, y^{\prime}\right) d x
$$

où $y$ est une fonction de $\mathbb{R}$ dans $\mathbb{R}, f$ est une fonction de $\mathbb{R}^{3}$ dans $\mathbb{R}$.

On suppose que la fonction $y$ vérifie $y\left(x_{0}\right)=y_{0}$ et $y\left(x_{1}\right)=y_{1}$. On suppose aussi que $y$ est dérivable et de dérivée continue $y^{\prime}$.

Si la fonction $y^{0}(x)$ est un extremum de $I(y)$, alors elle doit être solution de l'équation différentielle d'Euler-Lagrange

$$
f_{y}-\frac{d}{d x} f_{y^{\prime}}=0
$$

Dans le cas des fonctions à plusieurs variable, on suppose que $I(u)$ est de la forme :

$$
\begin{gathered}
I(u)=\int_{\Omega} f\left(x, y, u, u_{x}, u_{y}\right) d x d y \\
\text { avec } \forall(x, y) \in \partial \Omega u(x, y)=u_{0}(x, y)
\end{gathered}
$$


où $u$ possède des dérivées partielles continues $u_{x}$ et $u_{y}$.

L'équation d'Euler-Lagrange qui est une condition nécessaire pour obtenir un extremum de $I(u)$ est donnée par :

$$
f_{u}-\frac{d}{d x} f_{u_{x}}-\frac{d}{d y} f_{u_{y}}=0
$$

\section{Démonstration :}

Soit $u^{0}$ un extremum de $I$.

Soit $h(x, y)$ une fonction de $\mathbb{R}^{2}$ dans $\mathbb{R}$ différentiable et de dérivées partielles continues, vérifiant

$$
\forall \bar{x} \in \partial \Omega, h(\bar{x})=0
$$

Pour $\epsilon \in \mathbb{R}$, on pose

$$
\begin{gathered}
u_{\epsilon}(x, y)=u^{0}(x, y)+\epsilon h(x, y) \\
I\left(u_{\epsilon}\right)=F(\epsilon)=\int_{\Omega} f\left(x, y, u+\epsilon h, u_{x}+\epsilon h_{x}, u_{y}+\epsilon h_{y}\right) d x d y
\end{gathered}
$$

D'après l'hypothèse d'extremum pour $u^{0}$, on doit avoir $\mathrm{F}^{\prime}(0)=0$.

$$
\begin{aligned}
F^{\prime}(\epsilon) & =\int_{\Omega} \frac{d f}{d \epsilon} d x d y \\
& =\int_{\Omega}\left[f_{u} h+f_{u_{x}} h_{x}+f_{u_{y}} h_{y}\right] d x d y \\
& =\int_{\Omega}\left[f_{u} h+\frac{d}{d x}\left(f_{u_{x}} h\right)-\frac{d}{d x} f_{u_{x}} h+\frac{d}{d y}\left(f_{u_{y}} h_{y}\right)-\frac{d}{d y} f_{u_{y}} h\right] d x d y \\
& \stackrel{[25]}{=} \int_{\Omega}\left[\left(f_{u}-\frac{d f_{u_{x}}}{d x}-\frac{d f_{u_{y}}}{d y}\right) h\right] d x d y+\underbrace{\int_{0}^{b}\left[f_{u_{x}} h\right]_{0}^{a} d y}_{0}+\underbrace{\int_{0}^{a}\left[f_{u_{y}} h\right]_{0}^{b} d x}_{0}
\end{aligned}
$$

Dans les équations ci-dessus, les valeurs de $f$ sont calculées en $\left(x, y, u+\epsilon h, u_{x}+\right.$ $\left.\epsilon h_{x}, u_{y}+\epsilon h_{y}\right)$.

Lorsque $\epsilon$ vaut 0 , on obtient en $\left(x, y, u_{x}, u_{y}\right)$

$$
\forall h \text { vérifiant les conditions (25), } F^{\prime}(0)=\left\langle f_{u}-\frac{d}{d x} f_{u_{x}}-\frac{d}{d y} f_{u_{y}}, h\right\rangle
$$

On en déduit l'équation d'Euler-Lagrange ( 24 ). 


\section{A.2.3 Retour à la minimisation de $E$}

L'équation 23 peut se décomposer une somme de deux termes $E(u)=E_{1}(u)+$ $\lambda E_{2}(u)$ avec $E_{1}(u)=\frac{1}{2}\|v-P u\|^{2}$ et $E_{2}(u)=\int_{\Omega} \Phi(|\nabla u|) d \Omega$.

Le minimum de l'énergie vérifie alors $\nabla E=\nabla E_{1}+\lambda \nabla E_{2}=0$, avec:

$$
\begin{array}{rll}
\nabla E_{1}(u) & =-P^{*}(v-P u) \\
& \text { car } & \\
\frac{E_{1}(u+\epsilon h)-E_{1}(u)}{\epsilon} & =-<P h, v-P u>+O(\epsilon) \\
& =<h,-P^{*}(v-P u)>+O(\epsilon)
\end{array}
$$

où $P^{*}$ représente l'opérateur adjoint de $\mathrm{P}$.

En outre,

$$
\begin{aligned}
\nabla E_{2}(u) & =-\operatorname{div}\left(\Phi^{\prime}(|\nabla u|) \frac{\nabla u}{|\nabla u|}\right) \\
\nabla E_{2}(u) & \stackrel{\text { car }}{\stackrel{[24}{=}}-\frac{d}{d x} f_{u_{x}}-\frac{d}{d y} f_{u_{y}} \\
\text { où } f\left(u_{x}, u_{y}\right) & =\Phi\left(\sqrt{u_{x}^{2}+u_{y}^{2}}\right) \\
f_{u_{x}}\left(u_{x}, u_{y}\right) & =\frac{u_{x}}{\sqrt{u_{x}^{2}+u_{y}^{2}}} \Phi^{\prime}\left(\sqrt{u_{x}^{2}+u_{y}^{2}}\right)=\frac{u_{x}}{|\nabla u|} \Phi^{\prime}(|\nabla u|)
\end{aligned}
$$

On obtient alors pour $\nabla E=0$ l'équation suivante :

$$
P^{*}(v-P u)+\lambda \operatorname{div}\left(\Phi^{\prime}(|\nabla u|) \frac{\nabla u}{|\nabla u|}\right)=0
$$

Il est intéressant de réécrire l'expression de $E_{2}(u)$ en fonction de $u_{\xi \xi}$ et de $u_{\eta \eta}$ qui sont les dérivées secondes directionnelles de $u(\bar{x})$ dans la direction du gradient $\xi=\frac{\nabla u}{\nabla u}$ et dans la direction $\eta$ orthogonale au gradient. On a dans un premier temps :

$$
\begin{aligned}
u_{\xi \xi} & =\nabla\left(u_{\xi}\right) \cdot \xi \\
& =\nabla(\nabla u \cdot \xi) \cdot \xi
\end{aligned}
$$




$$
\begin{aligned}
& =\nabla\left(\frac{\nabla u \cdot \nabla u}{|\nabla u|}\right) \cdot \frac{\nabla u}{|\nabla u|} \\
& =\nabla(|\nabla u|) \cdot \frac{\nabla u}{|\nabla u|}
\end{aligned}
$$

Et d'autre part,

$$
u_{\eta \eta}=\Delta u-u_{\xi \xi}
$$

On rappelle l'égalité suivante (où $\alpha$ est un réel et $\overrightarrow{\mathbf{v}}$ un vecteur)

$$
\operatorname{div}(\alpha \cdot \overrightarrow{\mathbf{v}})=\alpha \cdot \operatorname{div}(\overrightarrow{\mathbf{v}})+<\nabla \alpha, \overrightarrow{\mathbf{v}}>
$$

ainsi que

$$
\nabla(F(s))=F^{\prime}(s) \nabla s
$$

où $\mathrm{F}$ est une fonction de $\mathbb{R}$ dans $\mathbb{R}$ et $s$ une fonction de $\mathbb{R}^{n}$ dans $\mathbb{R}$.

On peut alors réécrire

$$
\operatorname{div}\left(\Phi^{\prime}(|\nabla u|) \frac{\nabla u}{|\nabla u|}\right) \stackrel{[29]}{=} \Phi^{\prime}(|\nabla u|) \operatorname{div}\left(\frac{\nabla u}{|\nabla u|}\right)+\nabla\left(\Phi^{\prime}(|\nabla u|)\right) \cdot \frac{\nabla u}{|\nabla u|}
$$

Le deuxième terme s'écrit :

$$
\begin{aligned}
& \left.\nabla\left(\Phi^{\prime}(|\nabla u|)\right) . \xi \quad \stackrel{[30]}{=} \quad \Phi^{\prime \prime}(|\nabla u|) \nabla(|\nabla u|)\right) . \xi \\
& \stackrel{[27]}{=} \Phi^{\prime \prime}(|\nabla u|) u_{\xi \xi}
\end{aligned}
$$

Le premier terme s'écrit :

$$
\begin{aligned}
& \Phi^{\prime}(|\nabla u|) \operatorname{div}\left(\frac{\nabla u}{|\nabla u|}\right) \quad \stackrel{29]}{=} \Phi^{\prime}(|\nabla u|)\left(\frac{1}{|\nabla u|} \operatorname{div}(\nabla u)+\nabla\left(\frac{1}{|\nabla u|}\right) \cdot \nabla u\right) \\
& {\left[\stackrel{30]}{=} \frac{\Phi^{\prime}(|\nabla u|)}{|\nabla u|}\left(\Delta u-\nabla(|\nabla u|) \frac{\nabla u}{|\nabla u|}\right)\right.} \\
& {\left[\stackrel{27}{=} \quad \frac{\Phi^{\prime}(|\nabla u|)}{|\nabla u|}\left(\Delta u-u_{\xi \xi}\right)\right.} \\
& {[28] \quad \frac{\Phi^{\prime}(|\nabla u|)}{|\nabla u|} u_{\eta \eta}}
\end{aligned}
$$


On obtient donc

$$
P^{*}(v-P u)+\lambda\left(\Phi^{\prime \prime}(|\nabla u|) u_{\xi \xi}+\frac{\Phi^{\prime}(|\nabla u|)}{|\nabla u|} u_{\eta \eta}\right)=0 .
$$

Remarque

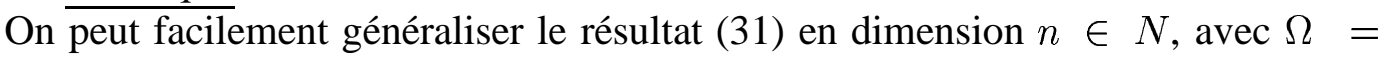
$\left(0, a_{1}\right) \times \cdots \times\left(0, a_{n}\right)$.

Pour cela, il suffit de remplacer $u_{\eta \eta}$ par la somme des n-1 dérivées secondes directionnelles selon $\eta_{1}, \cdots, \eta_{n-1}$, où $\left(\xi, \eta_{1}, \cdots, \eta_{n-1}\right)$ forment une base orthonormale de $\mathbb{R}^{n}$.

Cela se traduit par une diffusion toujours isotrope dans l'hyperplan orthogonal au gradient de l'intensité.

\section{A.3 Choix de la fonction de diffusion}

Le lien entre l'équation de diffusion 22 et l'équation 31 obtenue au chapitre 2 s'effectue en supprimant le premier terme d'attache aux données de 31 et en posant $\lambda=1$ et

$$
g(|\nabla u|)=\frac{\Phi^{\prime}(|\nabla u|)}{|\nabla u|}
$$

L'équation 22 s'interprète alors comme une descente de gradient le long d'une surface d'énergie $E(u)$ définie par :

$$
E(u)=\int_{\Omega} \Phi(|\nabla u|) d \Omega
$$

et elle peut mise sous la forme suivante :

$$
\frac{\partial u}{\partial t}=-\nabla E=\Phi^{\prime \prime}(|\nabla u|) u_{\xi \xi}+\frac{\Phi^{\prime}(|\nabla u|)}{|\nabla u|} u_{\eta \eta}
$$

\section{A.3.1 Critères de stabilité}

Afin d'assurer la stabilité du processus d'évolution quelles que soient les conditions initiales, la surface E(u) doit posséder un minimum global. 
Si l'on impose les deux contraintes 34 et 35 à la fonction $\Phi$ alors l'énergie E(u) sera convexe et la stabilité du processus sera assurée.

$$
\begin{aligned}
& \Phi^{\prime \prime}(|\nabla u|) \geq 0 \\
& \Phi^{\prime}(|\nabla u|) \geq 0
\end{aligned}
$$

En effet, le gradient étant une fonction linéaire (donc convexe) et la norme euclidienne étant convexe,

$$
\begin{array}{r}
\forall \lambda, \mu \in \mathbb{R}^{+}, \lambda+\mu=1, \\
\forall u, v \text { fonctions de } \mathbb{R}^{n} \text { dans } \mathbb{R} \\
|\nabla(\lambda u+\mu v)| \leq \lambda|\nabla u|+\mu|\nabla v|
\end{array}
$$

en outre, $\Phi$ est croissante d'après (35), donc

$$
\Phi(|\nabla(\lambda u+\mu v)|) \leq \Phi(\lambda|\nabla u|+\mu|\nabla v|)
$$

et $\Phi$ et $\int$ sont convexes, ce qui assure donc la convexité de E.

\section{A.3.2 Critères de restauration}

Le processus de diffusion anisotrope devrait idéalement satisfaire les deux critères suivants :

1. La diffusion doit s'effectuer de manière isotrope dans les régions homogènes, c'est-à-dire lorsque $|\nabla u|$ est proche de zéro.

2. Dans les zones à fort gradient, la diffusion ne doit s'effectuer que dans la direction $\eta$ qui est orthogonale au gradient de manière à conserver le contraste et renforcer les contours.

Ces deux critères s'interprètent par rapport à la fonction de diffusion $\Phi$ à l'aide de l'équation 33.

Le premier critère est équivalent à

$$
\lim _{x \rightarrow 0} \frac{\Phi^{\prime}(x)}{x}=\lim _{x \rightarrow 0} \Phi^{\prime \prime}(x)=\Phi^{\prime \prime}(0)>0
$$


Et le deuxième critère est équivalent à

$$
\lim _{x \rightarrow \infty} \Phi^{\prime \prime}(x)=0 \text { et } \lim _{x \rightarrow \infty} \frac{\Phi^{\prime}(x)}{x}=\text { Constante }>0
$$

Ces deux conditions ne pouvent être réalisées simultanément puisque si $\Phi^{\prime \prime}(x)$ tend vers zéro quand $\mathrm{x}$ tend vers l'infini alors $\frac{\Phi^{\prime}(x)}{x}$ tend aussi vers zéro.

Un critère plus large consiste à imposer à $\Phi^{\prime \prime}(x)$ de décroître plus rapidement que $\frac{\Phi^{\prime}(x)}{x}$ lorsque $\mathrm{x}$ tend vers l'infini :

$$
\lim _{x \rightarrow \infty} \Phi^{\prime \prime}(x)=0 \text { et } \lim _{x \rightarrow \infty} \frac{\Phi^{\prime}(x)}{x}=0 \text { et } \lim _{x \rightarrow \infty} \frac{x \Phi^{\prime \prime}(x)}{\Phi^{\prime}(x)}=0
$$

\section{A.3.3 Différentes fonctions proposées}

Ces différentes fonctions sont représentées graphiquement en annexe.

\begin{tabular}{|l||c|c|c|c|}
\hline Auteur & $\Phi(s)$ & $\frac{\Phi^{\prime}(s)}{s}$ & $\Phi^{\prime \prime}(s)$ & $\frac{s \Phi^{\prime \prime}(s)}{\Phi^{\prime}(s)}$ \\
\hline \hline $\begin{array}{l}\text { Perona-Malik } \\
\text { [PM90] }\end{array}$ & $\frac{-k^{2}}{2}\left(e^{-\left(\frac{s}{k}\right)^{2}}-1\right)$ & $e^{-\left(\frac{s}{k}\right)^{2}}$ & $\left(1-2\left(\frac{s}{k}\right)^{2}\right) e^{-\left(\frac{s}{k}\right)^{2}}$ & $1-2\left(\frac{s}{k}\right)^{2}$ \\
\hline $\begin{array}{l}\text { Perona-Malik } \\
\text { [PM90] }\end{array}$ & $\frac{k^{2}}{2} \log \left(1+\left(\frac{s}{k}\right)^{2}\right)$ & $\frac{1}{1+\left(\frac{s}{k}\right)^{2}}$ & $\frac{k^{2}\left(k^{2}-s^{2}\right)}{\left(k^{2}+s^{2}\right)^{2}}$ & $\frac{k^{2}-s^{2}}{k^{2}+s^{2}}$ \\
\hline $\begin{array}{l}\text { Geman et Rey- } \\
\text { nolds [GR84] }\end{array}$ & $\frac{\left(\frac{s}{k}\right)^{2}}{1+\left(\frac{s}{k}\right)^{2}}$ & $\frac{2 k^{2}}{\left(k^{2}+s^{2}\right)^{2}}$ & $-\frac{2 k^{2}\left(-k^{2}+s^{3}\right)}{\left(k^{2}+s^{2}\right)^{2}}$ & $-\frac{k^{2}-s^{3}}{k^{2}+s^{2}}$ \\
\hline Tikhonov & $\frac{s^{2}}{2}$ & 1 & 1 & 1 \\
\hline $\begin{array}{l}\text { Green [Gre90] } \\
\log \cosh (s / k)\end{array}$ & $\frac{\tanh (s / k)}{k s}$ & $k^{-2}\left(\cosh \left(\frac{s}{k}\right)\right)^{-2}$ & $\frac{s}{k \sinh \left(\frac{s}{k}\right) \cosh \left(\frac{s}{k}\right)}$ \\
\hline Rudin [ROF92] & $\sqrt{1+\left(\frac{s}{k}\right)^{2}}-1$ & $\frac{1}{\sqrt{1+(s / k)^{2}}} k^{-2}$ & $\frac{|k|}{\left(k^{2}+s^{2}\right)^{3 / 2}}$ & $\frac{k^{2}}{k^{2}+s^{2}}$ \\
\hline $\begin{array}{l}\text { Aubert } \\
\text { [CABFB94] }\end{array}$ & $\cdots$ & $\mathrm{g}(\mathrm{s})$ & $(1-\mathrm{h}(\mathrm{s})) \mathrm{g}(\mathrm{s})$ & $1-\mathrm{h}(\mathrm{s})$ \\
\hline $\begin{array}{l}\text { Alvarez } \\
\text { [ALM92] }\end{array}$ & $\sqrt{1}$ & & \\
\hline
\end{tabular}

INRIA 
Alvarez ne propose pas une fonction $\Phi$ mais deux fonctions $g()$ et $h()$ vérifiant les propriétés suivantes :

$$
h(s)= \begin{cases}1 & \text { si } s \geq 2 e \\ 0 & \text { si } s \leq e\end{cases}
$$

et

$$
g(s)= \begin{cases}1 & \text { lorsque } s \rightarrow 0 \\ 0 & \text { lorsque } s \rightarrow \infty\end{cases}
$$

Si l'on impose en outre à $\mathrm{h}(\mathrm{s})$ de rester inférieure à 1 (sur l'intervalle [e,2e]) et à g(s) d'être positive, alors les conditions de stabilité sont vérifiées.

Cependant, cette approche ne permet plus d'interpréter le processus de diffusion comme un algorithme de minimisation d'une énergie dépendante de la fonction $\Phi$, à moins d'imposer

$$
h(s)=-\frac{g^{\prime}(s)}{g(s)}
$$

Le tableau ci-dessous donne les conditions vérifiées par chacune de ces fonctions de diffusion :

\begin{tabular}{|l||c|c|c|c|}
\hline \multicolumn{1}{|c||}{} & \multicolumn{2}{c|}{ stabilité } & \multicolumn{2}{c|}{ restauration } \\
Auteur & condition 34 & condition 35 & condition 36 & condition 38 \\
\hline \hline Perona-Malik & & $X$ & $X$ & \\
\hline Perona-Malik & & $X$ & $X$ & \\
\hline Geman Reynolds & & $X$ & $X$ & \\
\hline Tikhonov & $X$ & $X$ & $X$ & \\
\hline Green $\left(^{*}\right)$ & $X$ & $X$ & $X$ & $X$ \\
\hline Rudin & $X$ & $X$ & & $X$ \\
\hline Aubert $\left(^{*}\right)$ & $X$ & $X$ & $X$ & $X$ \\
\hline Alvarez $\left(^{*}\right)$ & $X$ & $X$ & $X$ & $X$ \\
\hline
\end{tabular}

Seules les 3 fonctions signalées par un astérisque vérifient toutes les conditions de stabilité et de restauration de l'image. 


\section{A.4 Mise en œuvre du processus de diffusion}

L'équation de diffusion anisotrope (22) :

$$
\begin{aligned}
\frac{\partial u}{\partial t} & =\operatorname{div}(g(|\nabla u|) \cdot \nabla(u)) \\
& =\operatorname{div}\left(\frac{\Phi^{\prime}(|\nabla u|)}{|\nabla u|} \cdot \nabla(u)\right)
\end{aligned}
$$

est réécrite en introduisant la fonction $c(\bar{x}, t)=(g(|\nabla u|))(\bar{x}, t)$, où $\bar{x}$ est un vecteur de $\mathbb{R}^{n}$ représentant la position d'un pixel de l'image, et $t \in \mathbb{R}$ est le paramètre d'évolution du processus :

$$
\frac{\partial u}{\partial t}(\bar{x}, t)=\operatorname{div}(c(\bar{x}, t) \cdot \nabla(u)(\bar{x}, t))
$$

\section{A.4.1 Approximation numérique en dimension 1}

En dimension 1, l'équation 39 s'écrit :

$$
\begin{aligned}
\frac{\partial u}{\partial t}(x, t) & =\frac{\partial}{\partial x}(c(x, t) \cdot \nabla(u)(x, t)) \\
& \approx \frac{\partial}{\partial x}\left(c(x, t) \cdot \frac{1}{d x}\left(u\left(x+\frac{d x}{2}, t\right)-u\left(x-\frac{d x}{2}, t\right)\right)\right) \\
& \approx \frac{1}{d x^{2}} \cdot\left[c\left(x+\frac{d x}{2}, t\right) \cdot(u(x+d x, t)-u(x, t))-\right. \\
& \left.\quad c\left(x-\frac{d x}{2}, t\right) \cdot(u(x, t)-u(x-d x, t))\right] \\
& \approx \varphi_{\text {droite }}-\varphi_{\text {gauche }} \operatorname{si} d x=1
\end{aligned}
$$

En notant $\varphi(x, t)$ la fonction $c(x, t) \frac{\partial u}{\partial x}(x, t)$,

$$
\varphi_{\text {droite }}=\varphi\left(x+\frac{d x}{2}, t\right) \text { et } \varphi_{\text {gauche }}=\varphi\left(x-\frac{d x}{2}, t\right) .
$$

\section{A.4.2 Généralisation en dimension $n$}

Le résultat précédent se généralise facilement en dimension n, et correspond à la somme des variation de la fonction $\varphi$ selon chaque dimension. 


$$
\begin{aligned}
& \frac{\partial u}{\partial t}(\bar{x}, t)=\operatorname{div}(c(\bar{x}, t) \cdot \nabla(u)(\bar{x}, t)) \\
&=\sum_{i=1}^{n} \frac{\partial}{\partial x_{i}}\left(c(\bar{x}, t) \cdot \frac{\partial u}{\partial x_{i}}(\bar{x}, t)\right) \\
& \approx \sum_{i=1}^{n} \frac{\partial}{\partial x_{i}}\left(c(\bar{x}, t) \cdot \frac{1}{d x_{i}}\left(u\left(\bar{x}+\frac{d x_{i}}{2}, t\right)-u\left(\bar{x}-\frac{d x_{i}}{2}, t\right)\right)\right) \\
& \approx \sum_{i=1}^{n} \frac{1}{d x_{i}^{2}} \cdot\left[c\left(\bar{x}+\frac{d x_{i}}{2}, t\right) \cdot\left(u\left(\bar{x}+d x_{i}, t\right)-u(\bar{x}, t)\right)-\right. \\
& \approx \quad \sum_{i=1}^{n} \varphi_{x_{i}^{+}}-\varphi_{x_{i}^{-}} \operatorname{si} \forall i, d x_{i}=1 \\
& \text { noté } \quad(\delta u)(\bar{x}, t)
\end{aligned}
$$

En notant $\varphi(\bar{x}, t)$ le vecteur $c(\bar{x}, t) \nabla(u)(\bar{x}, t)$,

$$
\varphi_{x_{i}^{+}}=\varphi_{x_{i}}\left(\bar{x}+\frac{d x_{i}}{2}, t\right) \text { et } \varphi_{x_{i}^{-}}=\varphi_{x_{i}}\left(\bar{x}-\frac{d x_{i}}{2}, t\right)
$$

\section{A.4.3 Algorithme}

La diffusion a été programmée en dimensions 1, 2 et 3 . Le processus consiste à itérer un certain nombre de fois l'équation

$$
\forall \bar{x} \in \Omega, u(\bar{x}, t+d t)=u(\bar{x}, t)+d t .(\delta u)(\bar{x}, t)
$$

Le calcul de $(\delta u)(\bar{x}, t)$ n'est cependant pas immédiat, deux versions ont été réalisées :

1. La première avec $\mathrm{dx}=1$ pixel donc $d x_{i}=$ la taille d'un pixel selon la $i^{\text {me }}$ dimension,

2. La deuxième avec $\mathrm{dx}=2$ pixels. 
Dans la première version, le calcul de $(\delta u)(\bar{x}, t)$ se fait directement pour chaque pixel (ou voxel) mais l'expression $c\left(\bar{x} \pm \frac{d x_{i}}{2}, t\right)$ nécessite d'évaluer la norme du gradient de l'image au milieu de pixels voisins.

Cette norme est calculée à l'aide de la moyenne des gradients de l'image en chacun des deux pixels.

La deuxième version utilise une valeur plus importante pour $\mathrm{dx}$, ce qui entraîne une perte de précision dans le calcul des dérivées, mais permet d'améliorer le temps de calcul.

En effet, cette version permet de mémoriser dans un premier temps les valeurs de $c(\bar{x}, t)$ pour tout $\bar{x} \in \Omega$ puis ensuite de calculer plus rapidement $(\delta u)(\bar{x}, t)$, chaque valeur de $c(\bar{x}, t)$ étant utilisée $2 \mathrm{n}$ fois pour tout $\bar{x} \in \Omega$.

Première version de l'algorithme

Algorithme 1 ( calcul de $(\delta u)(\bar{x}, t)$ version 1 ) :

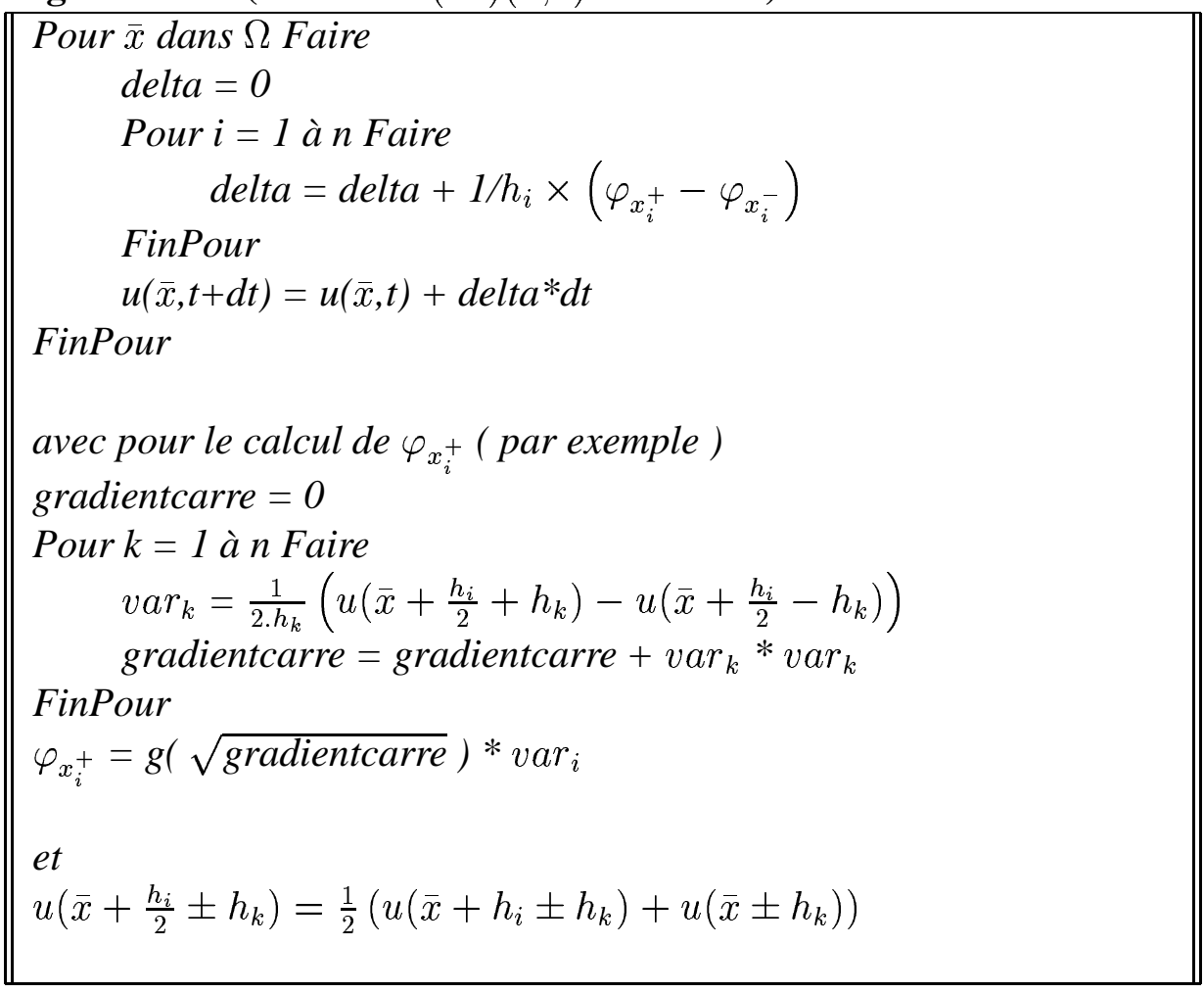

Le calcul de complexité donne les résultats suivant, avec $p$ le nombre de points de l'image et $n$ la dimension de l'image : 
- nombre de $\sqrt{\cdots}=2 \mathrm{np}$,

- nombre d'accès à l'image $=24 n p$,

- nombre d'additions $=n p(n+27)$,

- nombre de multiplications ou divisions $=n p(n+14)$,

- nombre d'appels à la fonction de diffusion $g()=2 n p$.

$\underline{\text { Deuxième version }}$

Algorithme 2 ( calcul de $(\delta u)(\bar{x}, t)$ version 2 ) :

Première Partie : Calcul des $c(\bar{x}, t)$

Pour $\bar{x}$ dans $\Omega$ Faire

Pour $k=1$ à $n$ Faire

$$
\begin{aligned}
& d=\frac{1}{2 \cdot h_{k}}\left(u\left(\bar{x}+h_{k}\right)-u\left(\bar{x}-h_{k}\right)\right) \\
& \text { gradientcarre }=\text { gradientcarre }+d * d
\end{aligned}
$$

FinPour

$c(\bar{x})=g(\sqrt{\text { gradientcarre }})$

FinPour

Deuxième partie : Calcul de la nouvelle image

Pour $\bar{x}$ dans $\Omega$ Faire

$$
\text { delta }=0
$$

Pour $k=1$ à $n$ Faire

$$
\begin{gathered}
\text { delta }=\text { delta }+\frac{1}{4 . h_{k}^{2}}\left[c\left(\bar{x}+h_{k}\right) *\left(u\left(\bar{x}+2 . h_{k}\right)-u(\bar{x})\right)-\right. \\
\left.c\left(\bar{x}+h_{k}\right) *\left(u(\bar{x})-u\left(\bar{x}-2 . h_{k}\right)\right)\right]
\end{gathered}
$$

FinPour

$u(\bar{x}, t+d t)=u(\bar{x}, t+d t)+d e l t a * d t$

FinPour 
Le calcul de complexité donne les résultats suivant, avec $p$ le nombre de points de l'image et $n$ la dimension de l'image :

- nombre de $\sqrt{\cdots}=\mathrm{p}$,

- nombre d'accès à l'image $=4 \mathrm{np}$,

- nombre d'additions $=p(8 n-2)$,

- nombre de multiplications ou divisions $=\mathrm{n}(5 \mathrm{n}+1)$,

- nombre d'appels à la fonction de diffusion $\mathrm{g}()=\mathrm{p}$.

On constate que ces valeurs sont bien meilleures que celles de l'algorithme précédent, pour les raisons expliquées précédemment.

La dimension restant en pratique égale à 1,2 ou 3, elle peut être considérée comme constante et la complexité sur le plan théorique est de $\mathrm{O}(\mathrm{p})$. En outre, ces algorithmes ne permettent pas de calculer le gradient sur les bords de l'image, et il faudrait alors diffuser dans le plan orthogonal au bord (en 3D) ou dans la droite orthogonale (en 2D).

\section{A.5 Principaux paramètres de la procédure}

\section{A.5.1 Le seuil $k$ et la fonction de diffusion}

Evolution d'une pente

On crée une fonction de la forme 'arc-tangente', qui simule une variation importante de l'intensité de l'image (pente). Les figures suivantes permettent d'interpréter l'évolution de cette image.

En dimension 1, le processus de diffusion anisotrope s'écrit :

$$
\frac{\partial u}{\partial t}=\Phi^{\prime \prime}\left(\frac{\partial u}{\partial x}\right) \frac{\partial^{2} u}{\partial x^{2}}
$$


Si l'on note pour t fixé, $\mathrm{u}(\mathrm{x}, \mathrm{t})=\mathrm{u}(\mathrm{x}), d u=\Phi^{\prime \prime}\left(u^{\prime}(x)\right) u^{\prime \prime}(x)$

La figure 8 contient l'image $\mathrm{u}(\mathrm{x})$, et ses dérivées u' et $\mathrm{u}$ '.

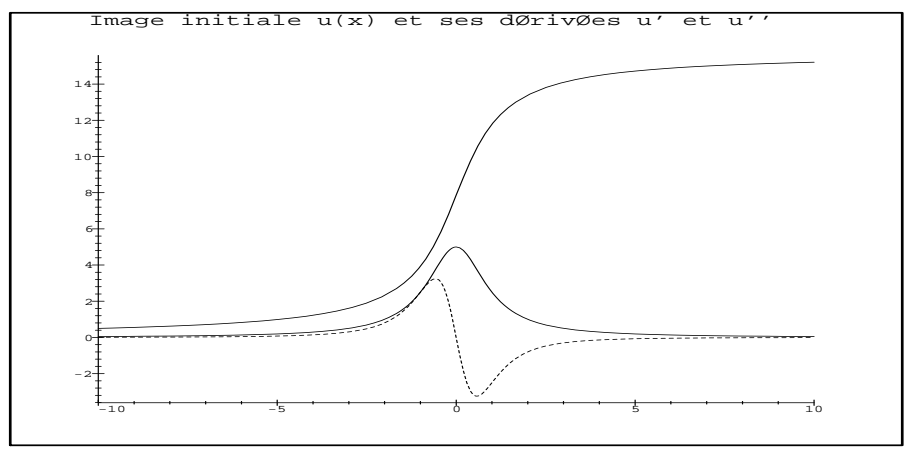

Figure 8: fonction pente

Afin de bien comprendre le processus, on a représenté les quatre fonctions suivantes :

1. la fonction de diffusion $\Phi^{\prime \prime}$,

2. le coefficient $\Phi^{\prime \prime}\left(u^{\prime}\right)$,

3. la variation de l'image $d u=\Phi^{\prime \prime}\left(u^{\prime}\right) u^{\prime \prime}$,

4. et la nouvelle pente $u+d u$.

Fonction de diffusion stable (figure 9)

Le processus est stable mais lorsque l'on itère à l'infini, il tend vers une image de gradient nul (minimum de la surface d'énergie).

Les gradients faibles $(<$ au seuil $\mathrm{k}$ ) sont beaucoup plus atténués que les gradients forts $(\gg k)$.

Fonction de diffusion instable (figure 10)

Le processus est instable mais il possède la propriété de rehausser la pente si la norme du gradient est bien supérieure à $\mathrm{k}$.

La figure 11 montre bien la différence d'évolution d'une même pente pour la fonction de Green stable et pour la fonction de Perona et Malik 1 instable. Nous 


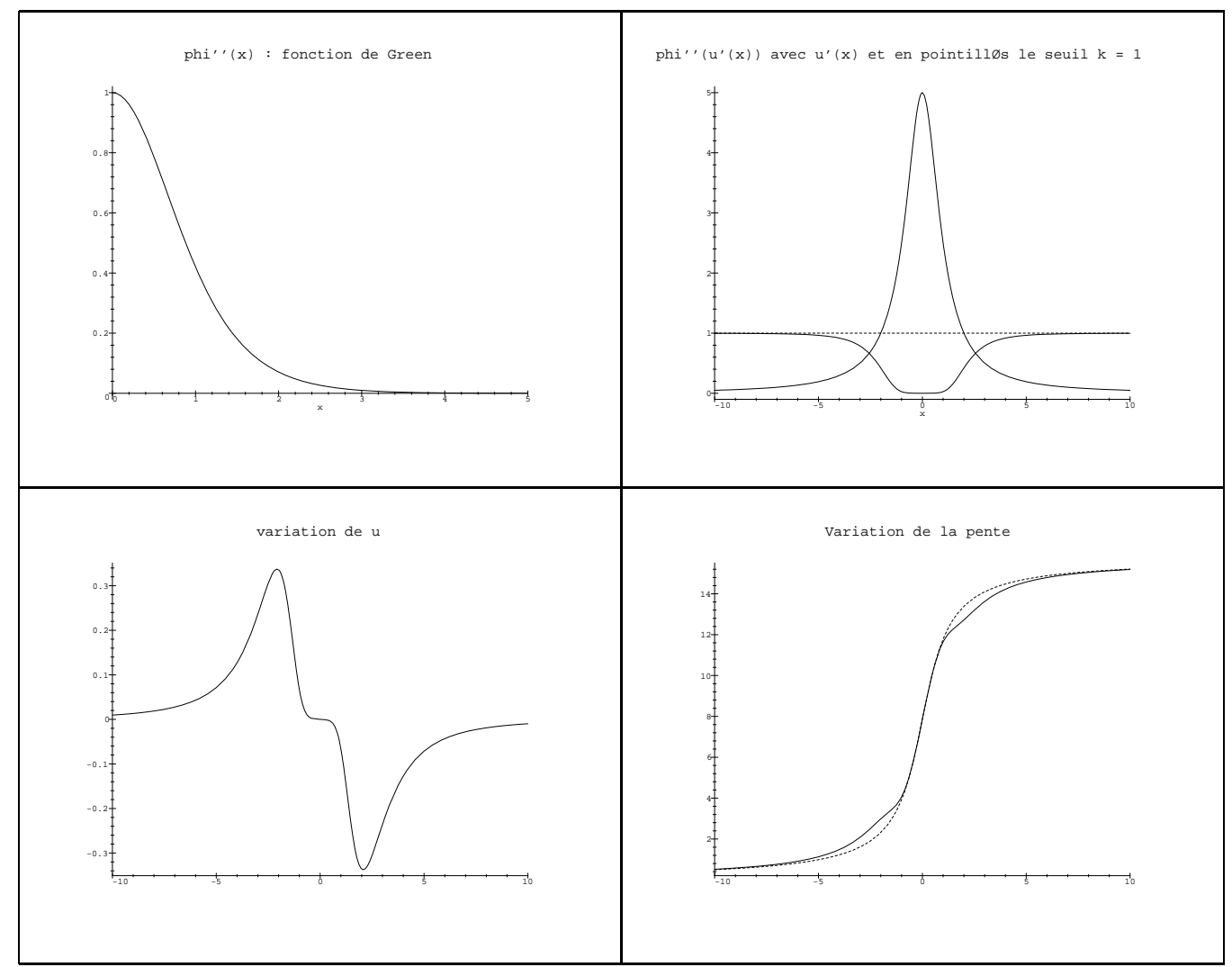

Figure 9: en haut à gauche fonction de Green, stable; en haut à droite coefficient de diffusion quasi nul si u' > $2 \mathrm{k}$; en bas à gauche variation de $\mathrm{u}$; en bas à droite nouvelle pente. 


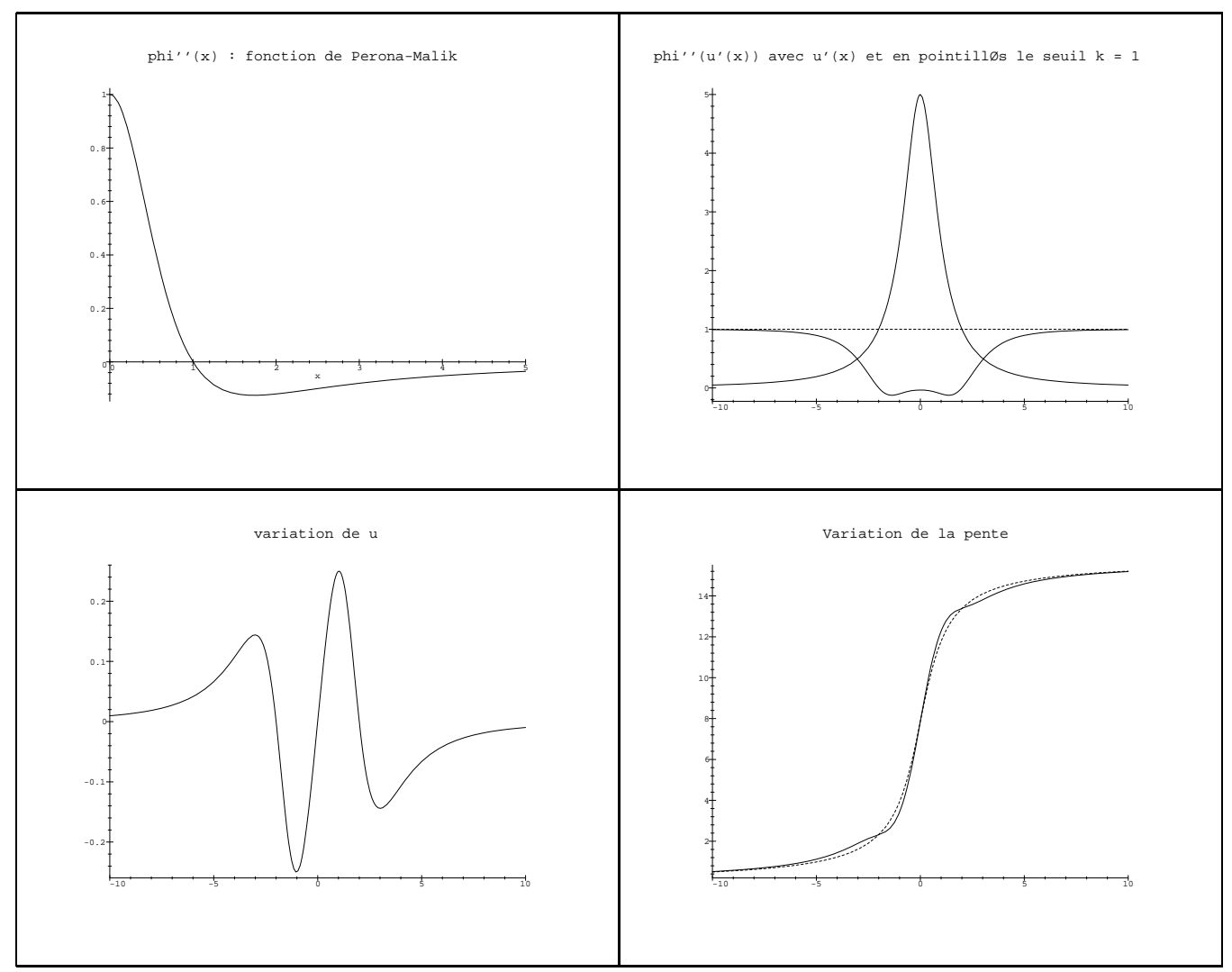

Figure 10: en haut à gauche fonction rationnelle de Perona-Malik, instable; en haut à droite le coefficient de diffusion devient négatif lorsque la pente dépasse le seuil k; en bas à gauche variation de $\mathrm{u}$; en bas à droite nouvelle pente. 
constatons que la fonction instable a rendue la pente verticale après un nombre élevé d'itérations, mais qu'elle a aussi créé des oscillations parasites.

En pratique la valeur du seuil k dépend directement de l'écart-type du bruit dans l'image. La diffusion anisotrope ne sera efficace que si les variations du gradient introduites par le bruit restent inférieures aux valeurs du gradient qui caractérisent les frontières des différents tissus.

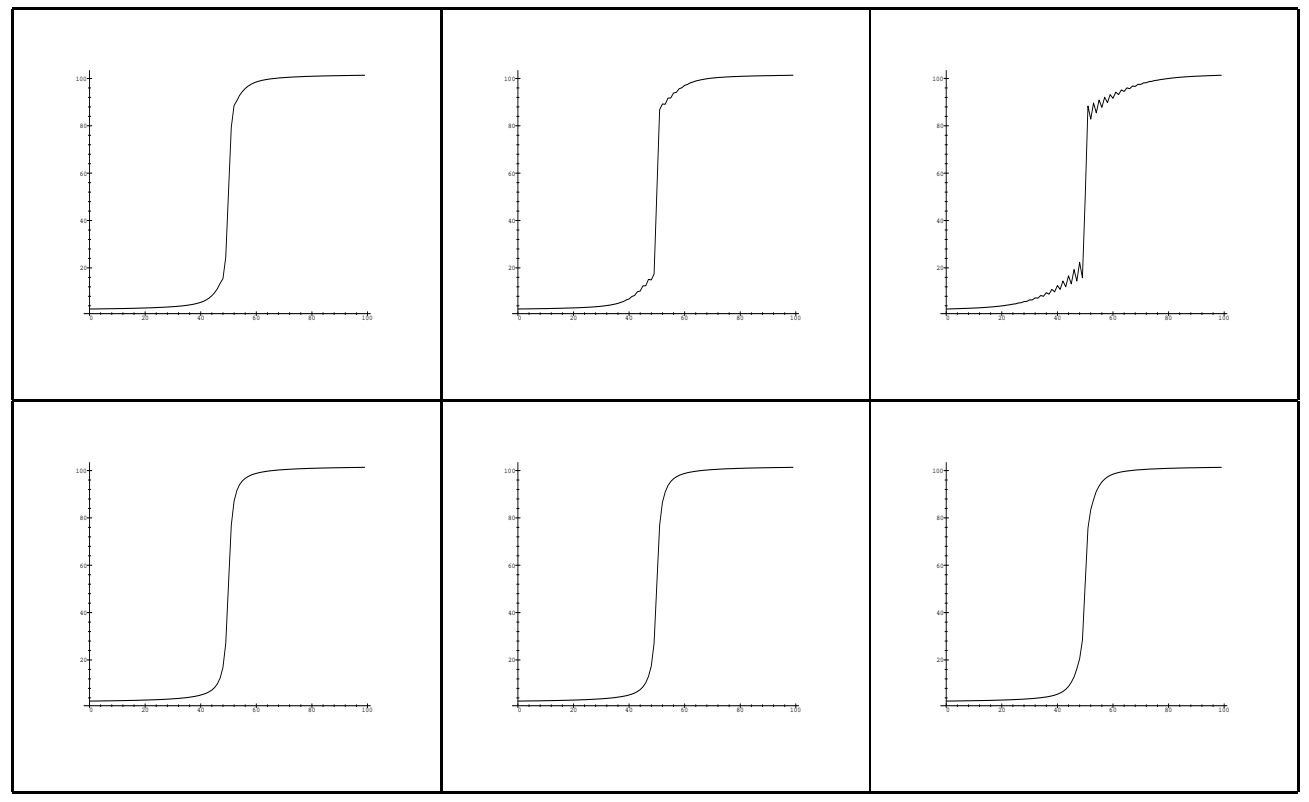

Figure 11: Evolution d'une pente selon la fonction de diffusion et le nombre de pas avec un seuil $\mathrm{k}=5$ ligne du haut fonction de Perona et Malik 1 (instable); ligne du bas fonction de Green (stable); colonne de gauche résultat après 10 itérations; colonne du milieu résultat après 50 itérations; colonne du droite résultat après 300 itérations.

\section{A.5.2 Le nombre de pas}

La figure 12 présente l'évolution du processus de diffusion anisotrope sur une ligne d'une image IRM du cerveau. Les images ont été obtenues avec un seuil $\mathrm{k}=1$ et un paramètre $\mathrm{dt}=0.3$ après $0, . ., 8,20,30$ et 45 itérations. 


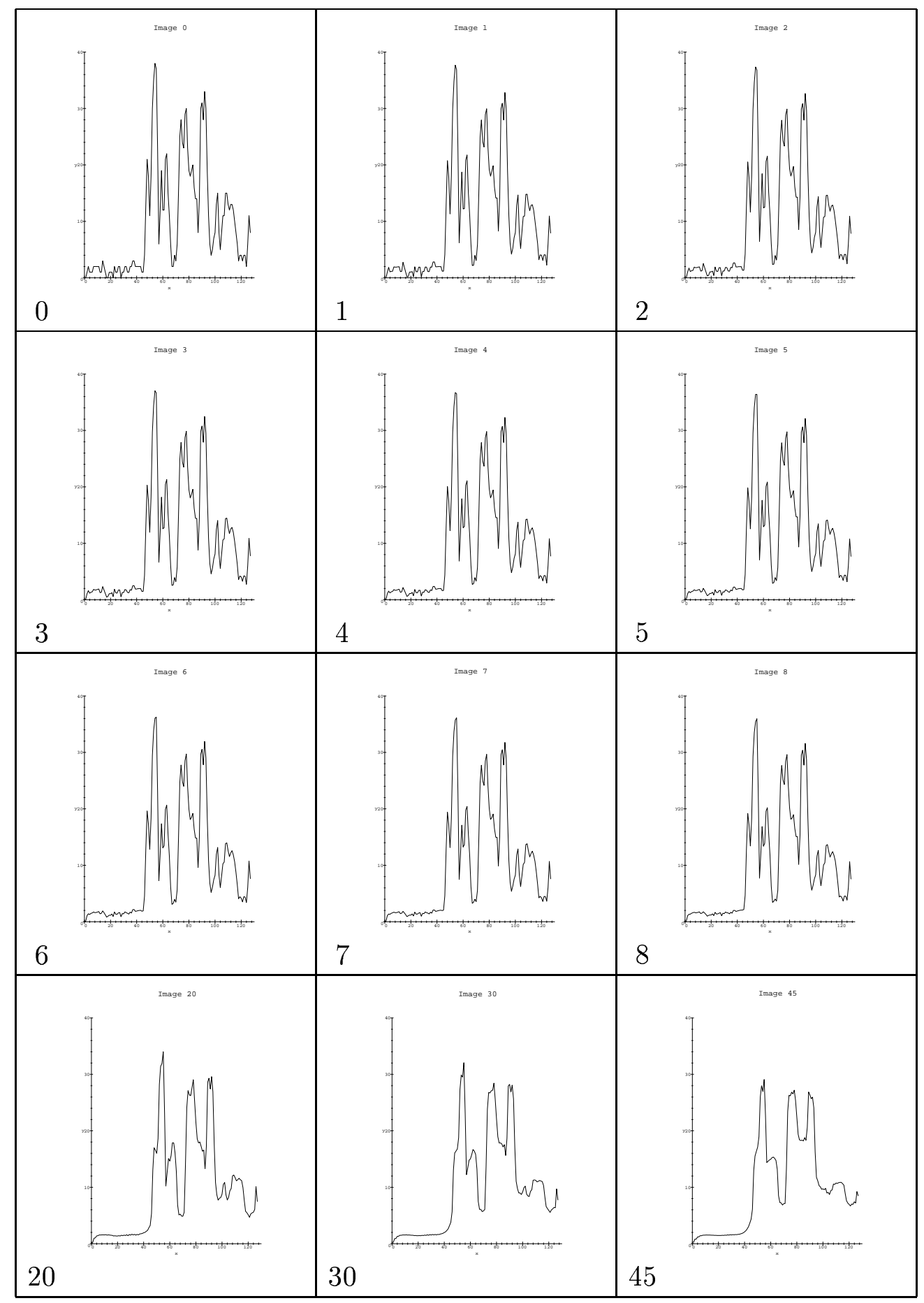

Figure 12: Evolution d'une ligne d'intensité prise sur une image IRM du cerveau. Diffusion anisotrope avec $\mathrm{k}=1, \mathrm{dt}=0.3$; itérations $0 . .8,20,30,45$. 
Lorsque $x \in[0 . .40]$, l'intensité correspond à celle du fond de l'image. Le bruit dans cette zone est éliminé rapidement grâce à une diffusion importante.

Dans l'image 8 , le bruit pour $\mathrm{x}<40$ a été bien atténué et les contraste de l'image pour $\mathrm{x}>40$ sont conservés.

Par contre, la perte d'information par rapport à l'image initiale est mise en évidence après un nombre élévé d'itérations (image 45) où les pics et les creux de la fonction d'intensité sont atténués.

\section{A.6 Autre approche}

Lorsque $\Phi^{\prime \prime}$ est négatif, la fonction de diffusion peut réhausser le gradient de l'image et donc le contraste, mais cela introduit une instabilité. En effet, l'équation de diffusion agit alors comme une équation inverse de la chaleur et en outre les discontinuités introduites par le bruit peuvent être accentuées.

L'algorithme peut alors avoir un effet contraire à celui souhaité, c'est-à-dire amplifier le bruit au lieu de le supprimer.

Afin de résoudre ce problème, Catté, Lions, Morel et Coll [CCLM92] proposent de calculer le coefficient de diffusion non pas sur la norme du gradient de l'image, mais plutôt sur la norme du gradient de l'image lissée :

$$
\frac{\partial u}{\partial t}=\operatorname{div}\left(g\left(\left|\nabla\left(G_{\sigma} * u\right)\right|\right) \nabla u\right)
$$

Dans cette équation, $G_{\sigma}$ représente une fonction gaussienne d'écart-type $\sigma$ et $*$ est le produit de convolution.

Cette approche permet de résoudre le problème des discontinuités locales du gradient liées au bruit. La stabilité et la convergence de ce nouveau modèle sont démontrés dans [CCLM92].

Les auteurs proposent de fixer l'arrêt de l'algorithme à une échelle t de l'ordre du paramètre $\sigma$ de la Gaussienne.

La figure 13 permet de comparer l'évolution d'une pente avec l'équation de diffusion proposée par Pérona et Malik (approche "classique") et avec celle proposée 
par Catté. Le seuil k est fixé à 2 et l'écart-type de la gaussienne vaut 1 . Le résultat après 300 itérations montre l'avantage de la méthode la méthode de Catté qui permet d'utiliser une fonction qui "réhausse" la pente tout en conservant un processus stable. Cependant, lorsque le nombre d'itérations tend vers l'infini, les deux méthodes convergent vers une fonction constante, même si la méthode de Catté qui préserve mieux la pente converge moins vite vers cette solution (figure 13 après 5000 itérations).

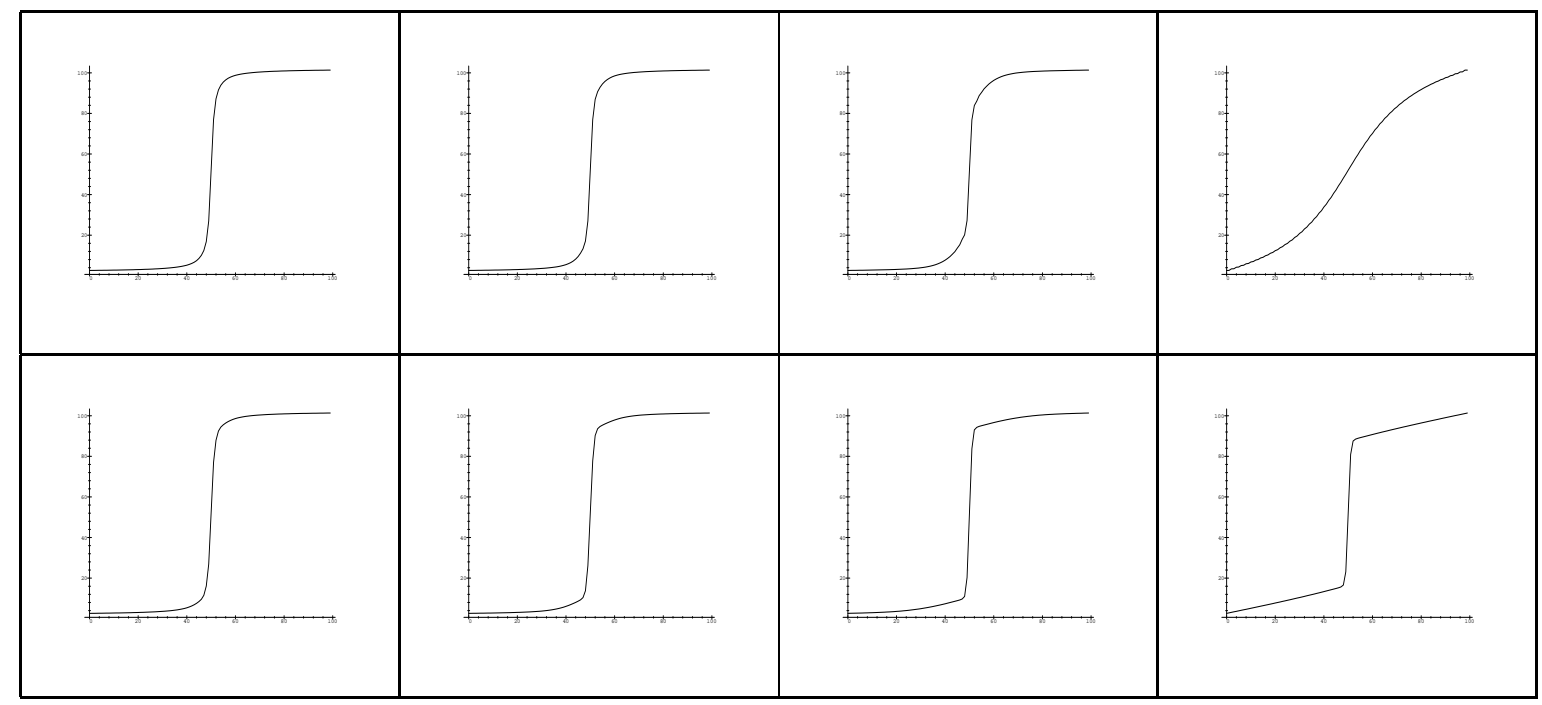

Figure 13: Comparaison de la méthode de Catté (paragraphe A.6) et de la méthode de Pérona et Malik, avec un seuil k = 2 ligne du haut fonction de Green (stable); ligne du bas fonction de Perona et Malik 1 avec le processus de diffusion présenté en A.6; de gauche à droite résultats après 10,50,300 et 5000 itérations.

\section{A.7 Défauts et perspectives}

La mise en oeuvre du processus de diffusion anisotrope fondée sur des travaux récents ([GKKJ92], [DF95]) a donné de bons résultats pour l'amélioration de la qualité des images et du rapport signal / bruit .

L'étude des différents paramètres de l'algorithme met cependant en évidence des améliorations possibles à ce processus : 
- permettre au processus de converger vers une image segmentée ou linéaire par parties. Nordström propose dans [Nor90] d'introduire un terme d'attache aux données dans le processus de diffusion,

- proposer une valeur pour le seuil k de l'ordre de l'écart-type du bruit,

- fixer un critère d'arrêt de l'algorithme,

- étendre la diffusion isotrope dans le plan tangent aux isosurfaces en une diffusion anisotrope, et obtenir trois coefficients de diffusion dans les images tridimensionnelles. 


\section{A.8 Représentation graphique des fonctions de diffusion}

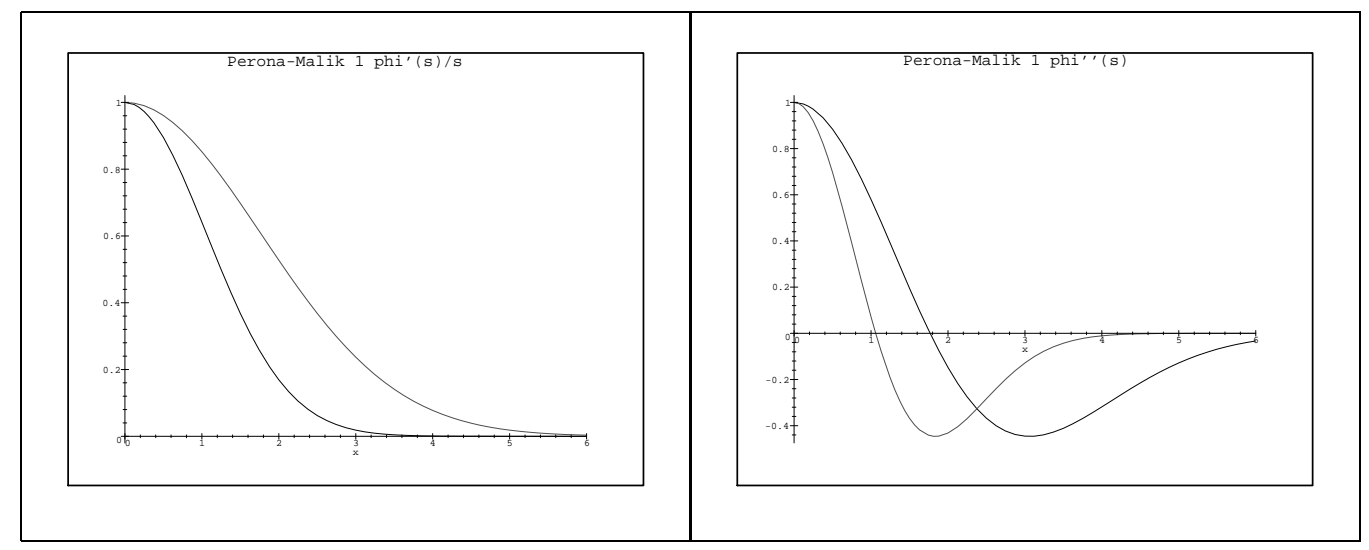

Figure 14: Perona Malik 1

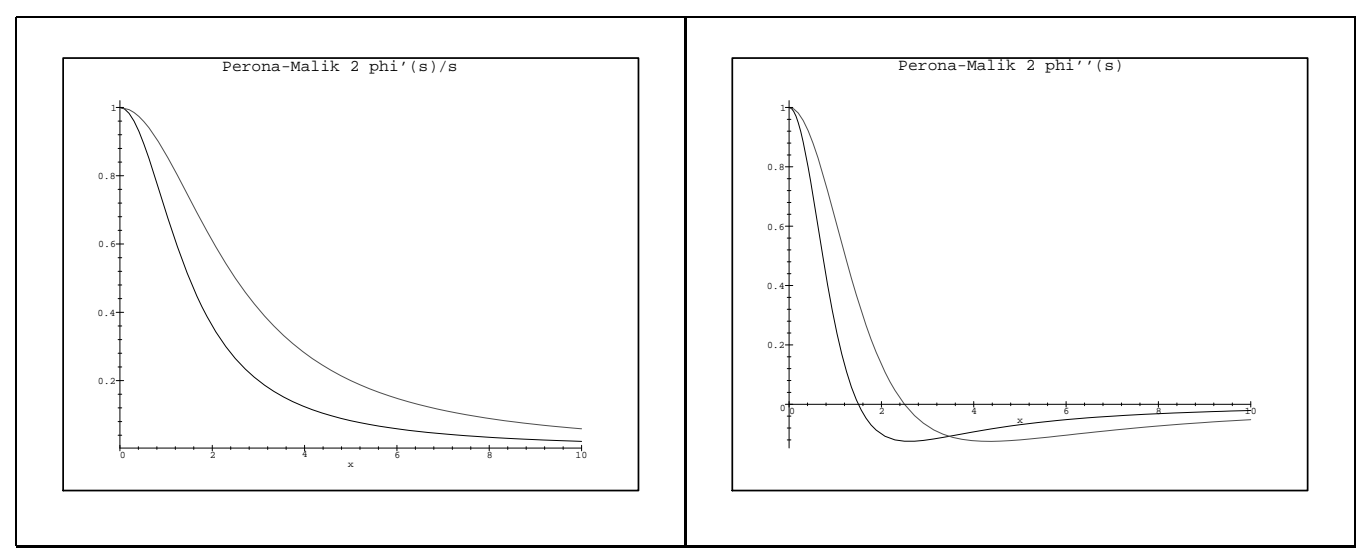

Figure 15: Perona Malik 2 


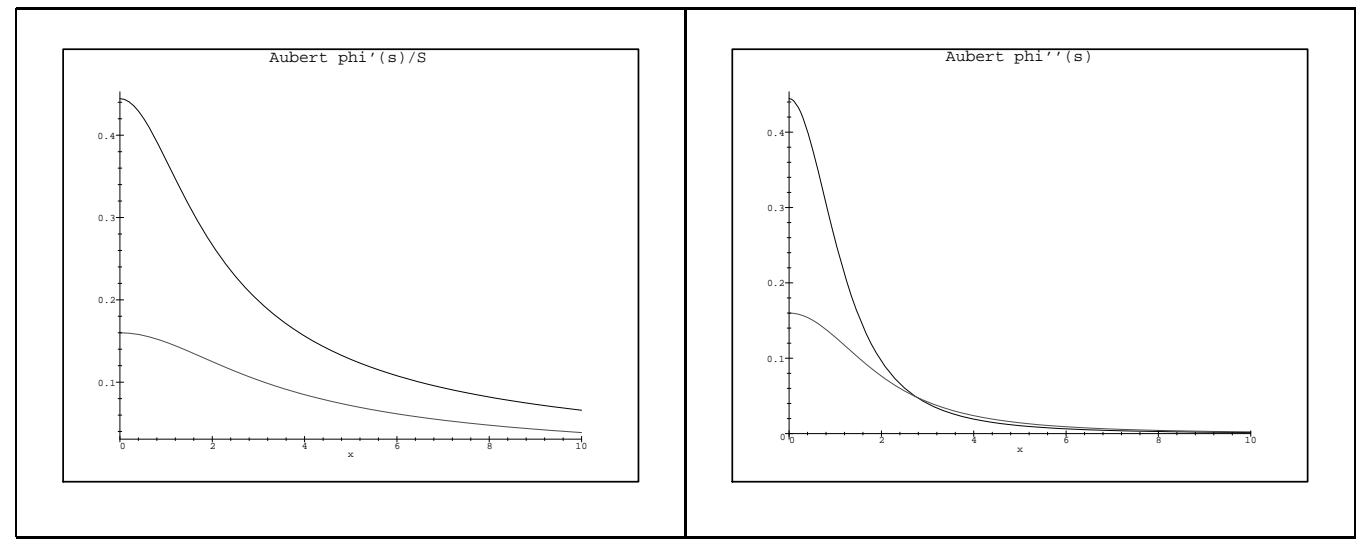

Figure 16: Aubert

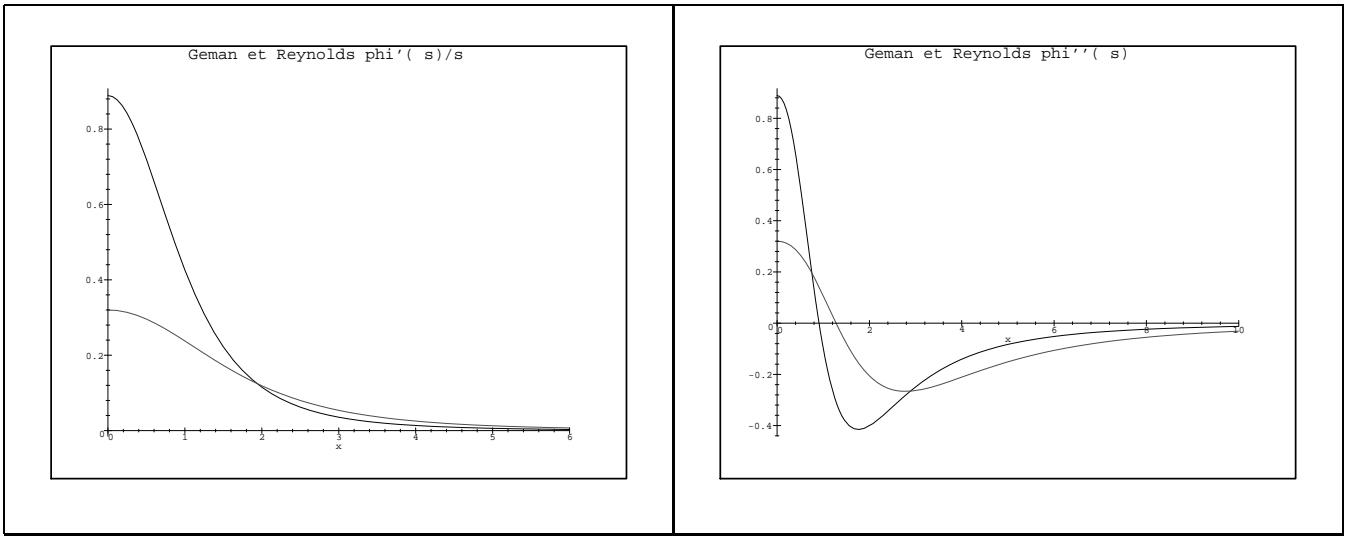

Figure 17: Geman et Reynolds

INRIA 


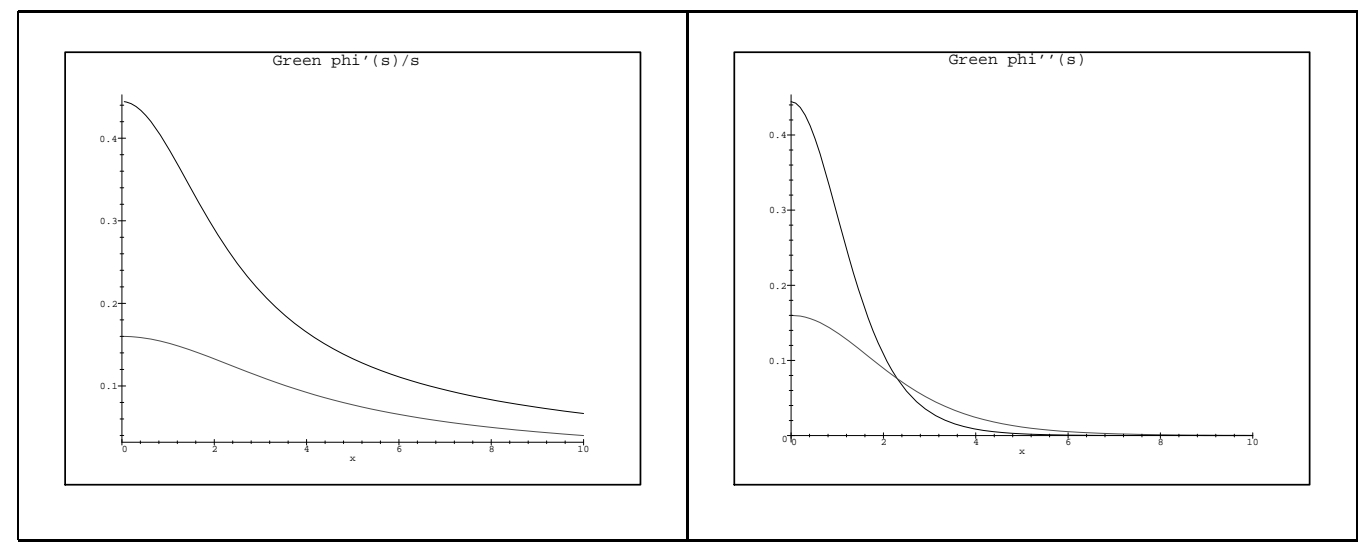

Figure 18: Green

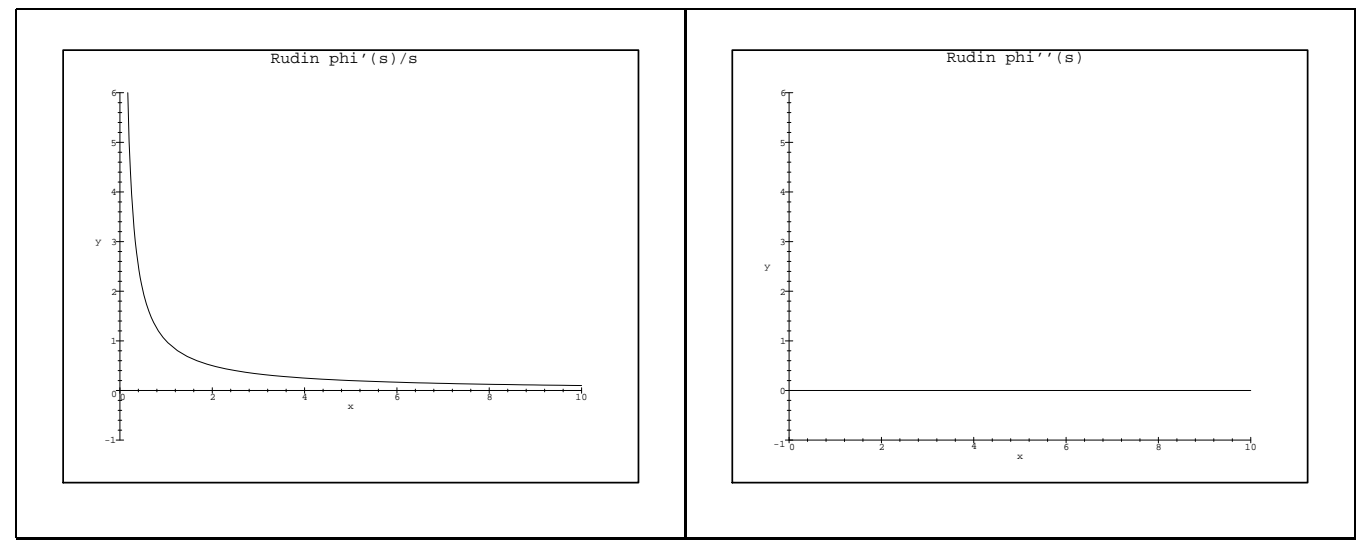

Figure 19: Rudin 


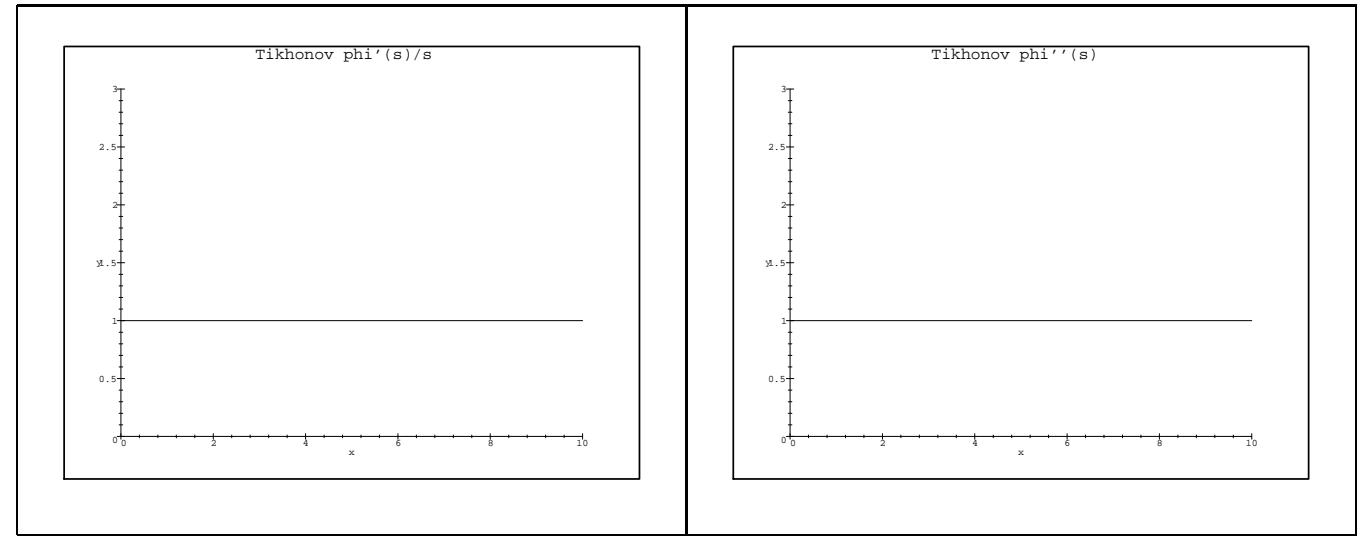

Figure 20: Tikhonov 


\section{References}

[ALM92] L. Alvarez, P.L. Lions, and J.M. Morel. Image selective smoothing and edge detection by nonlinear diffusion. SIAM J. Numer. Anal., 29(3):845-866, 1992.

[CABFB94] P. Charbonnier, G. Aubert, M. Blanc-Ferraud, and M. Barlaud. TwoDeterministic Half-Quadratic Regularization Algorithms for Computed Imaging. In IEEE Int. Conf. on Image Proc. ICIP, pages 168-172, Austin (Texas), November 1994.

[CCLM92] F. Catte, T. Coll, P.L. Lions, and J.M. Morel. Image Selective smoothing and edge detection by nonlinear diffusion. SIAM J. Numer. Anal., 29(1):182-193, February 1992.

[CS93] D.L. Chopp and J.A. Sethian. Flow under curvature; singularity formation minimal surfaces and geodesics. Journal Experimental Mathematics, 2(4):171-187, 1993.

[DF95] R. Deriche and O. Faugeras. Les EDP en Traitement des images et Vision par Ordinateur. Technical Report 2697, INRIA Sophia Antipolis, November 1995.

[GKKJ92] G. Gerig, O. Kübler, R. Kikinis, and F.A. Jolesz. Nonlinear Anisotropic Filtering of MRI Data. IEEE Transactions on medical imaging, 11(2), 1992.

[GR84] S. Geman and G. Reynolds. Constrained Restauration and the Recovery of discontinuities. IEEE Transactions on Pattern Analysis and Machine Intelligence, 6, 1984.

[Gra89] M.A. Grayson. A short note on the evolution of a surface by its mean curvature. Duke mathematical Journal, 58(3):555-558, June 1989.

[Gre90] P.J. Green. Bayesian Reconstruction From Emission Tomography Data Using A Modified EM Algorithm. IEEE Trans. Med. Imaging, 9, 1990. 
[Kri96] K. Krissian. Diffusion anisotrope d'images cerebrales 3D et Segmentation matière blanche / matière grise. Master's thesis, ENS Cachan et Paris XI, September 1996.

[Nor90] N. Nordström. Biased anisotropic diffusion - A unified regularization and diffusion approach to edge detection. Image Vision Comput., 8(4):318-327, 1990.

[NVV96] W.J. Niessen, K.L. Vincken, and M.A. Viergever. Comparison of multiscale representations for a linking-based image segmentation model. In Proceedings of MMBIA, pages 263-272, February 1996.

[PM90] P. Perona and J. Malik. Scale-Space and edge detection using anisotropic diffusion. IEEE Transactions on Pattern Analysis and Machine Intelligence, 12(7):629-639, July 1990.

[ROF92] L. Rudin, S. Osher, and E. Fatemi. Nonlinear total variation based noise removal algorithms. Physica D, 60:259-268, 1992.

[Rom96] B.M. Ter Haar Romeny. Introduction to Scale-Space Theory: Multiscale Geometric Image Analysis. Technical Report ICU-96-21, Utrecht University, September 1996.

[Set85] A.J. Sethian. Curvature and the evolution of fronts. Communications in Mathematical Physics, 101(487-499), 1985.

[TBFAB96] S. Teboul, L. Blanc-Féraud, G. Aubert, and M. Barlaud. Variational approach for edge-preserving regularization using coupled pde's. IEEE Transaction on image processing Special issue, October 1996.

[TG95] J.P. Thirion and A. Gourdon. Copmuting the differential characteristics of isointensity surfaces. Computer vision and image understanding, 61(2):190-202, March 1995. 


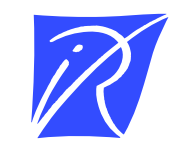

Unité de recherche INRIA Lorraine, Technopôle de Nancy-Brabois, Campus scientifique, 615 rue du Jardin Botanique, BP 101, 54600 VILLERS LÈS NANCY

Unité de recherche INRIA Rennes, Irisa, Campus universitaire de Beaulieu, 35042 RENNES Cedex

Unité de recherche INRIA Rhône-Alpes, 655, avenue de l'Europe, 38330 MONTBONNOT ST MARTIN

Unité de recherche INRIA Rocquencourt, Domaine de Voluceau, Rocquencourt, BP 105, 78153 LE CHESNAY Cedex

Unité de recherche INRIA Sophia Antipolis, 2004 route des Lucioles, BP 93, 06902 SOPHIA ANTIPOLIS Cedex

Éditeur

INRIA, Domaine de Voluceau, Rocquencourt, BP 105, 78153 LE CHESNAY Cedex (France)

ISSN 0249-6399 